\title{
A Multigroup Structural Equation Approach: A Demonstration by Testing Variation of Firm Profitability Across EU Samples
}

Organizational Research Methods 000(00) I-29

(C) The Author(s) 2009 IReprints and permission: sagepub.com/journalsPermissions.nav DOI: 10.1 I77/1094428109340433 http://orm.sagepub.com

@SAGE

\author{
Juan Carlos Bou,' and Albert Satorra ${ }^{2}$
}

\begin{abstract}
We extend standard methodology for multigroup mean and covariance structure (MACS) analysis to the case where assessment of across-group variation of model parameters is the focus of the study and the data deviate from standard assumptions. The proposed methods are applied to analyze an accounting profitability database covering more than 100,000 firms in the 15 European Union (EU) countries in the period 1999 to 2003. A multivariate model with permanent and dynamic latent components of profitability is used to assess across-country variation of firm level profitability and persistence. We show that there are substantial differences among these countries, despite the partial integration of their economies. Estimation of supplementary parameters are proposed as a way to characterize persistence in each country, as well as across-group variation of model parameters. This methodology is more widely applicable in international organizational research.
\end{abstract}

\section{Keywords}

returns on assets, persistence of profits, structural equation modeling, ML estimation, goodness-offit testing, multigroup analysis

\section{Introduction}

Model-based research in organizational and strategic management is often confronted with the need to analyze multigroup data (groups may be countries, industries, strategic groups, corporations, years, etc.) with a focus on assessing the distinct features of each group and variation across groups. In some contexts, for each group, there is need for models that can account for complex relationships among variables (simultaneous relationships, multiple indicators, etc.) and for endogenously defined parameters that capture essential features of the modeled phenomena. Structural equation models

\footnotetext{
'Department of Business Administration and Marketing, Universitat Jaume I, Castelló, Spain

${ }^{2}$ Department of Economics and Business, Universitat Pompeu Fabra, Barcelona, Spain and Barcelona GSE
}

\section{Corresponding Author:}

Juan Carlos Bou, Department of Business Administration and Marketing, Universitat Jaume I, Avinguda Sos Baynat s/n, I207I Castelló, Spain.

Email: bou@emp.uji.es 
(SEM) are specially suited for this purpose. SEM is a family of multivariate models that include simultaneous equations, factor analysis, and multilevel models, for single and multigroup data (see, e.g., Chan, 1998; Cheung \& Rensvold, 1999; Little, 1997; Ployhart \& Oswald, 2004; Vandenberg \& Lance, 2000, for applications and reviews of these models in organizational and management research). These models are also known as mean and covariance structures (MACSs), as usually both the means and covariances of a multivariate data set are involved in the analysis.

When confronted with multigroup data, researchers have also to decide between two alternatives: either to regard the groups as fixed, focusing the inferences on the particular groups in the data, or to regard them as random, that is, a sample drawn from a population of groups and focusing the inferences on this population. An important aspect of the latter is the variation across groups. A multilevel approach is better suited for data with many groups, whereas the fixed-effect approach, which includes multigroup analysis, is preferred when the number of groups is lower. However, the lack of any assessment of variation across groups is a drawback of the standard multigroup approach.

In this article, we address this problem by defining and estimating suitable measures of betweengroup variation for the multigroup approach and we apply it to an empirical data set of firm profit rates in the European Union (EU). Estimation of supplementary parameters (introduced in a section below) will enable researchers to characterize both the variation of firm profitability and the persistence of these differences at the various levels of the data hierarchy.

Previous studies that have analyzed the variation of firm profitability have applied variance decomposition techniques to assess the relative contribution of firms, corporations, and industries (e.g., Brush, Bromiley, \& Hendrickx, 1999; McGahan \& Porter, 1997; Roquebert, Phillips, \& Westfall, 1996; Rumelt, 1991) and also the contribution of country effect (Makino, Isobe, \& Chan, 2004). These studies offered controversial evidence on the relative size of the different components of profitability, with some of the differences attributed to the inadequacy of the statistical techniques used-in particular, the analysis of variance (ANOVA) and components of variance (COV) techniques - (see, e.g., Bowman \& Helfat, 2001; Brush \& Bromiley 1997; McGahan \& Porter, 2002, and also the first two rows in Table 1).

Recently, new statistical approaches have been incorporated to overcome the limitations of classical variance decomposition techniques. Bou and Satorra (2007), Hough (2006), Misangyi, Elms, Greckhamer, and Lepine (2006), and Short, Ketchen, Bennett, and du Toit (2006) have adopted multilevel analysis to assess the relative importance of corporation and industry effects. Even though the multilevel methods offer clear advantages for parsimoniously describing variation across higher level units, such as firms or industries (see fourth row in Table 1), the method relies on strong assumptions such as random variation across the higher level units. ${ }^{1}$ In some contexts, such as the one we address in the empirical part of this article, with a small number of second-level units (countries) of a fixed nature (they are not a sample of any population), the random assumption for multilevel analysis would be unwarranted. In our study, the sample sizes of firms within the countries are fairly large, which allows us to estimate a model in each second-level unit. In this context, the multigroup approach is more suitable. At present, however, the standard multigroup analysis lacks methodology that addresses the description of variation across groups or the variance decomposition approaches.

To overcome this limitation, supplementary parameters are introduced that assess variation in firm profitability and persistence across countries. In contrast to the multilevel approach, the fixed-effect approach adopted in the article fits a model in each of the second-level units (countries) using a multigroup approach (with parameter constraints across groups when substantively justified) and then defines new "supplementary" parameters to characterize the variation across the secondlevel units of the main features of the model (i.e., country-mean profitability or indices to measure the persistence of profit differences over time). These supplementary parameters are estimated with their corresponding standard errors. Using this approach, it is possible to provide the usual 


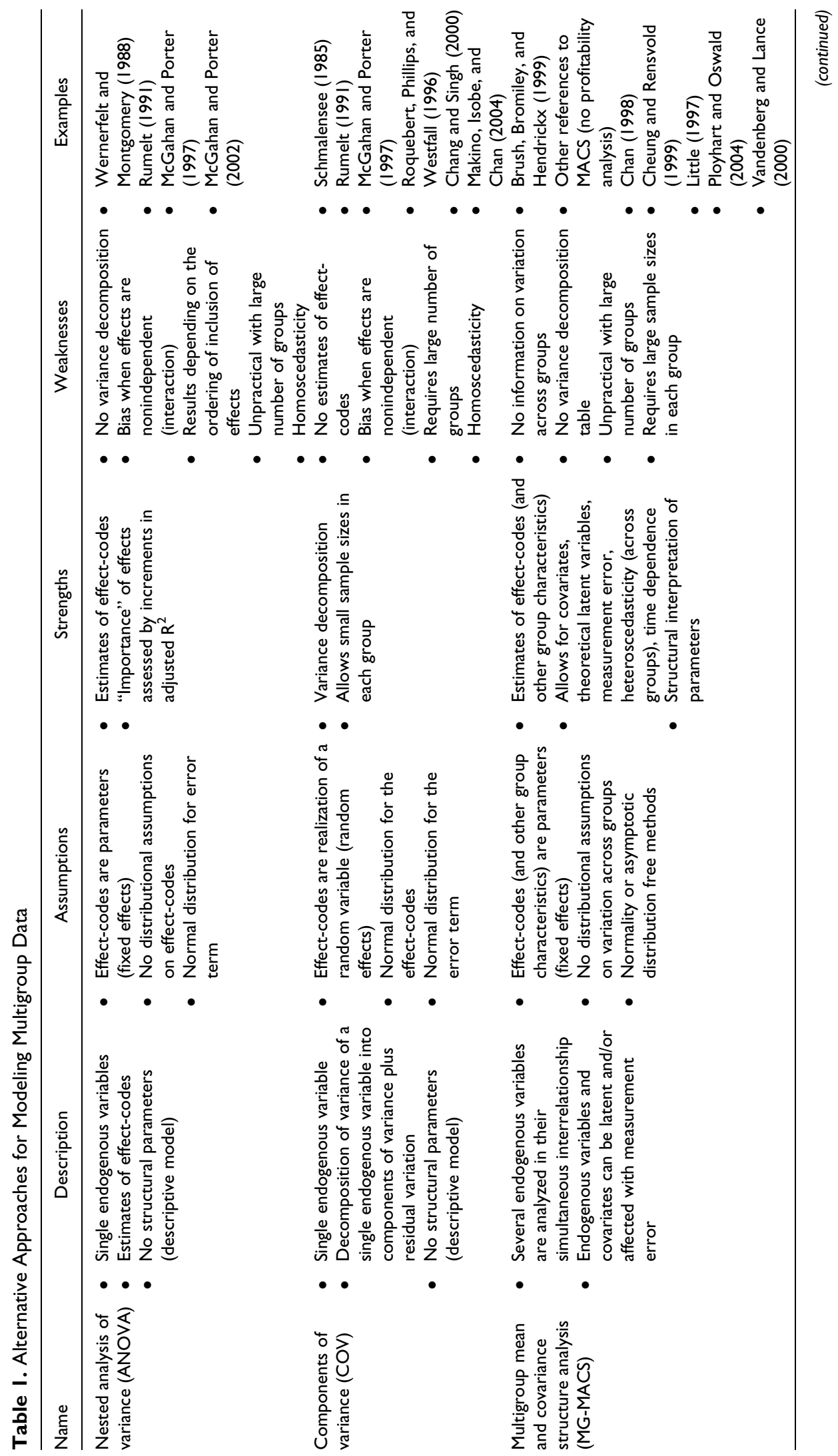




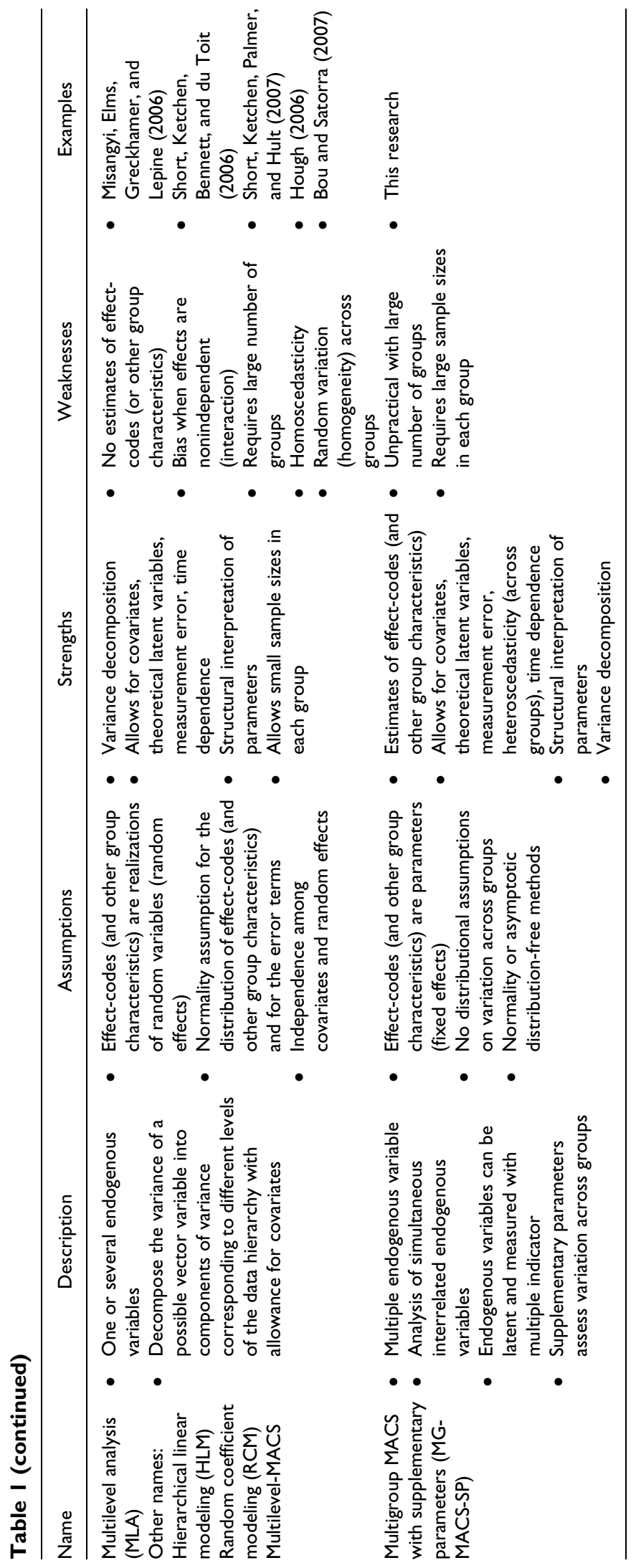


information obtained from multilevel analyses about variation across second-level units using mean, variance (and other model derived) parameters and to obtain detailed information on the model fit in each group. This latter information enables us to carry out in-depth comparisons among the set of countries. Moreover, no assumption needs to be made on random variation across groups.

Table 1 summarizes the alternative approaches for modeling multigroup data with summary descriptions of their strengths and weaknesses and references to applications. The last row of the table shows that the multigroup MACS with supplementary parameters we introduce in this article should be useful whenever the researcher is interested in variation across few well-identified groups and each group has a large sample size. We are not aware of any previous work that exploits the supplementary parameter approach to produce a decomposition of the variation across groups, as well as a detailed assessment of structural characteristics of the model in each group. In contrast to multilevel methodology, this variance decomposition is obtained without requiring any distributional assumptions. The approach we propose embraces the advantages of multigroup and multilevel analyses, because it offers effect-code estimates for each group (as ANOVA and multigroup MACS do, see rows 1 and 3 of Table 1) and also a variance decomposition table (as components of variance and multilevel analysis achieve; see rows 2 and 4 of Table 1).

Our methodology may help to build a bridge between multigroup and multilevel analyses, because the proposed methods can be carried out using currently available software for SEM analysis. In addition, the method addresses other practical issues such as the presence of missing data, nonnormality, or correction for intraindustry correlation.

By applying the proposed methodology to a relevant multinational database, our analysis also uncovers interesting differences among the EU-15 countries on the levels of firms' profitability and on their dynamics. We report variance decomposition by estimating the size of the firm, industry and country effects, and the shared variance accounted for by countries and industries. We estimate an index of persistence for each country and make inferences about its correlation with the overall profitability and country-level variables.

In the literature of country, industry, and firm effects, our integrative multigroup, multilevel, and longitudinal modeling approach provides new insight into different directions. First, the longitudinal model perspective allows us to decompose firm profitability into different dynamic components and, particularly, to distinguish between permanent and transient components. This decomposition permits a more proper test of changes in firm profitability over time. Second, the multigroup perspective allows a separate model to be estimated for each higher level unit (i.e., country, industry, or a combination of both), thus providing a detailed description of each effect for each country/industry. Third, the supplementary parameter approach allows variation across groups to be estimated and proper statistical tests of the significance of this variation to be carried out. Finally, with our approach, we can test the significance of covariates in explaining variation of profitability and persistence across countries or industries.

The article is structured as follows. Section 2 introduces the model and methodology. Section 3 describes the scope of the empirical analysis and the database. Section 4 presents the empirical results. Section 5 describes the findings. Section 6 closes the article with a discussion of the methodological and empirical results obtained.

\section{Models and Methodology}

\section{Modeling Firm Profitability}

As in Bou and Satorra (2007), we decompose firm profitability into several components: a competitive return that is common to all firms (the grand mean); a static or permanent firm-specific rent; a dynamic component (that varies over time); and an error/unexplained firm-by-year specific 
component. This decomposition is similar to the state dependence model by Anderson and Hsiao (1982) and the trait-state-error model by Kenny and Zautra $(1985,2001)$. Specifically, we have

$$
\begin{gathered}
\pi_{i t}=\alpha+\lambda_{t} P_{i}+A_{i t}+U_{i t} \\
A_{i t+1}=\beta_{t} A_{i t}+D_{i t},
\end{gathered}
$$

where $\pi_{i t}$ is the rate of return on assets (ROA) of firm $i$ at time $t ; \alpha$ is the overall mean profit rate ${ }^{2} P_{i}$ is the static or firm-specific permanent component whose variance captures long-run or sustainable differences between firms (i.e., differences that persist over a period longer than the length of the series); $A_{i t}$ is the dynamic or firm transitory component whose variance captures the firms' shortrun or nonsustainable rents that disappear over time as a result of competition. As in previous studies (Geroski \& Jacquemin, 1988; Jacobson, 1988; McGahan \& Porter, 1999; Mueller, 1986), $A_{i t}$ is assumed to follow a first-order autoregressive process. Component $U_{i t}$ is an idiosyncratic, unexplained, firm-by-year specific component. It encompasses all the specific and unstable circumstances that affect a firm's profit rate in one specific year, as well as a measurement error (Benston, 1985; Demsetz, 1979; Fisher \& McGowan, 1983). $D_{i t}$ is the disturbance component of the dynamic autoregressive part of the model. Here $A_{t}, P, U_{t}$ and $D_{t}$ are centered random variables, and the $U_{i t} \mathrm{~s}$ and $D_{i t} \mathrm{~s}$ are independent across $i$ and $t ; \lambda_{t}$ denotes the loading associated with the permanent component, and $\beta_{t}$ is the autoregressive parameter that can be associated with the "speed" at which the transient portion of profitability vanishes. The parameter $\beta$ can be interpreted as a "memory effect" (where $\beta=0$ is associated to zero "memory") of the time-dependent component of abnormal returns.

In our context, the model we finally estimate incorporates parameter restrictions that are not necessary under the general approach but are introduced to adhere to the theoretical and conceptual definitions of the components of profitability. The loadings $\left(\lambda_{t}\right)$ are set equal across $t$, reflecting that all years are equally important in the formation of the permanent component, that is, $P_{i}$ is defined as an adjusted across-time model-estimated average. The autoregressive parameters $\left(\beta_{t}\right)$ and the variances of the disturbance terms $\left(D_{i t}\right)$ are set constant across $t$, a restriction that enables a parsimonious decomposition of profitability into permanent and transitory components and allows us to compute an index of persistence (discussed later in this section). This ensures that the transitory component of profitability is stationary (it has a distribution that does not vary with $t$ ); this is an implicit condition used in most of the studies on the persistence of abnormal returns (see Mueller, 1990). The means of the variables, however, are assumed to vary across groups but remain constant over time, although different hypothesis about their invariance could be introduced by testing nested models.

Figure 1 shows a path-diagram representation of the model. In this graph, observed variables (ROA) are represented by square boxes, latent variables (unobservable components of returns) by circles, and the loadings and autoregressive parameters by single-headed arrows. The triangle represents the constant to 1.0, with the arrows departing from it representing the intercept parameter $\alpha$ of Equation 1, common to all $t$ in our specification.

The strength of the model lies in the fact that the variance of the components of profitability and the autoregressive coefficient $\beta$ are parameters with a direct substantive interpretation. Therefore, research questions concerning the size and the sustainability of between-firm differences can be formulated in terms of these "structural" parameters. In particular, we study whether there is a complete convergence of abnormal returns toward the mean (as the conventional economic theory assumes) or whether between-firm differences are permanent (i.e., persist throughout the period of the series). A complete convergence corresponds to zero variance of the permanent component. We also investigate the persistence of between-firm profitability differences, that is, we assess firms' relative ability to resist competitive forces and to achieve sustained competitive advantage. In the model, persistence is characterized by the relative size of the variances of the permanent and transitory components and the value of the $\beta$ coefficient. The higher the permanent component 


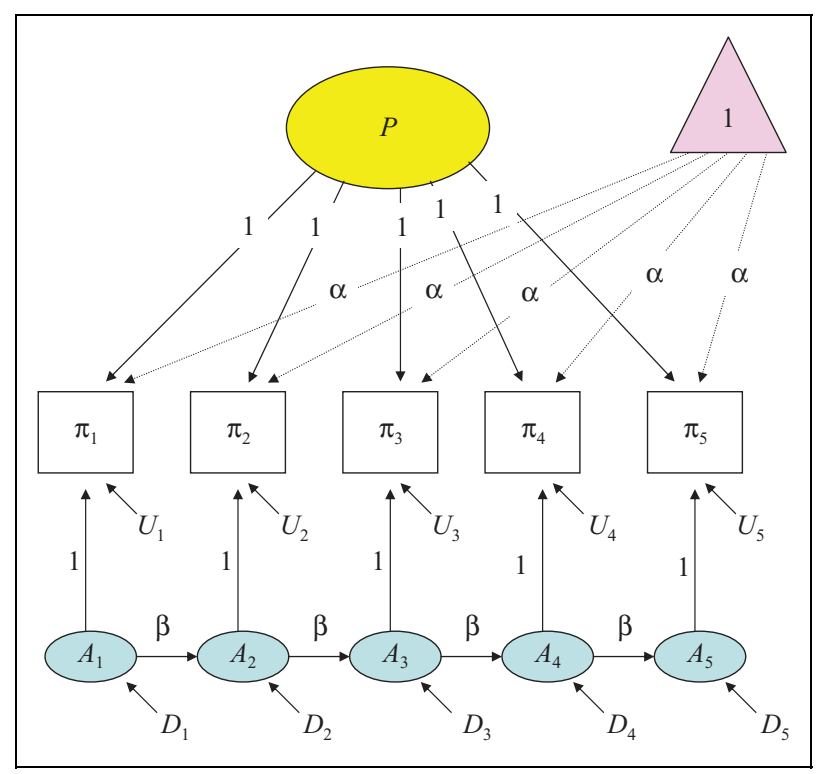

Figure I. Path-diagram of the model

(compared to the other two components) and the autoregressive coefficient, the higher the persistence of profit differences.

\section{The Model for Multigroup Data}

The variance decomposition into permanent and transitory components of Model 1 can be applied to different types of data, including single-group, multigroup, and multilevel data. When analyzing hierarchically structured data (e.g., firms nested in corporations, and/or industries) with a large number of higher level units and the assumptions of randomness are realistic (see Table 1), the Model 1 can be applied to each of the levels of analysis, obtaining a multilevel specification such as the one of Bou and Satorra (2007). However, when the objective is to compare a small set of specific groups of substantive interest (e.g., specific EU countries), it is more realistic to have a separate model with distinct sets of parameters for each country, some of them restricted by equalities across groups.

Hence, if we let superscript $(g)$ denote country, Model 1 for the different countries is

$$
\begin{aligned}
& \pi_{i t}^{(g)}=\alpha_{t}^{(g)}+\lambda_{t} P_{i}^{(g)}+A_{i t}^{(g)}+U_{i t}^{(g)} \\
& A_{i t+1}^{(g)}=\beta_{t}^{(g)} A_{i t}^{(g)}+D_{i t}^{(g)},
\end{aligned}
$$

$t=1,2, \ldots, T ; g=1,2, \ldots, G ; i=1,2, \ldots, n_{g}$, where the superindex $g$ denotes variation across countries of the parameters of the model. For example, in $\alpha_{t}^{(g)}$, the index $g$ denotes variation across countries of the mean firm profitability level.

In this formulation, countries are allowed to differ not only in their mean level of profitability but also in the regression parameter $\beta$ as well as in the variances of the various components of profitability. Multigroup models are valuable for an easily interpretable and detailed description of the variation at country level of the parameters characterizing the dynamic pattern of firm profitability (thus allowing modeling of country-level variation in persistence). Note that Equation 2 contemplates country-specific values for $\beta$ and for the variances of each of the (random) components of profitability: $P_{i}^{(g)}, A_{i 1}^{(g)}, U_{i t}^{(g)}$, and $D_{i t}^{(g)}$. A baseline multigroup model (MG) is specified from 
Table 2. Description of Models Considered

\begin{tabular}{lll}
\hline Model & \multicolumn{1}{c}{ Characteristics } & \multicolumn{1}{c}{ Description } \\
\hline SG & Single-group analysis & Information on country is lacking \\
MG & All parameters country-specific & Complete heterogeneity \\
MGI & $M G$ and ${ }^{a} \alpha^{(g)}=\alpha$ & Homogeneity of mean levels \\
MG2 & $M G$ and ${ }^{\mathrm{a}} \beta^{(g)}=\beta$ & Homogeneity of persistence \\
MG3 & $M G$ and ${ }^{\mathrm{a}} \operatorname{Var}\left(A_{t}^{(g)}\right)=\operatorname{Var}\left(A_{t}\right)$ and ${ }^{\mathrm{a}} \operatorname{Var}\left(P^{(g)}\right)=\operatorname{Var}(P)$ & Homoscedasticity \\
\hline
\end{tabular}

Note: $M G=$ multigroup.

${ }^{\mathrm{a}}$ For $\mathrm{g}=\mathrm{I}, \ldots, \mathrm{I} 5$.

Equation 2 when all the parameters are country-specific. Various MG submodels are obtained by introducing constraints on these sets of parameters allowing us to assess country-level differences in the means and variances. The various multigroup models considered are listed in Table 2.

In MG1, countries have the same mean level of profitability, but $\beta$ and the variance parameters vary across countries. In MG2, countries have identical slope parameters $\beta$ but may have different mean levels of profitability and variance parameters. In MG3, the countries have identical variances of the components $P_{i}^{(g)}$ and $A_{i t}^{(g)}$, but intercepts and slope parameters may be different. Likelihoodratio tests are used for model comparison.

In the empirical analysis, we consider the case where the parameters of the model differ not only across countries but also across sectors or types of industries. Such analysis will enable us to assess how much variation of both the average profitability and the persistence can be attributed to country, to sector, and to the sum of the two.

\section{The Supplementary Parameters Approach (SPA)}

One major target of the analysis is to assess variation across groups (countries) of the parameters of the model. A simple way to assess such variation is to compute the mean and variance across groups for the target parameters. For example, to assess across-group variation in the average level of profitability $\mu_{g}$, we compute the mean level of profitability across groups, that is

$$
\overline{\mu_{g}}=\sum_{g=1}^{G} \mu_{g} / G
$$

as well as the variance parameter

$$
\operatorname{Var}\left(\mu_{g}\right)=\sum_{g=1}^{G}\left(\mu_{g}-\overline{\mu_{g}}\right)^{2} / G .
$$

Country-level variation is described by new supplementary parameters (say $\gamma \mathrm{s}$ ) that are functions of the vector $\theta$ of parameters for the multigroup model; that is, $\gamma=g(\theta)$, where $g()$ is a function that is assumed to be continuously differentiable, such as the sample mean or the variance of Equations 3 and 4. In the empirical analysis, we also contemplate $g$ to be a function that evaluates an specific aspect of the model such as, for example, a persistency index for each country. A distinctive feature of our approach is that we compute estimates of the supplementary parameters with their standard errors (or their asymptotic variance matrix, when $g()$ is a $p$-valued function and thus $\gamma$ is a vector). The standard errors will turn out to be essential for assessing the significance of variation across groups and for comparing the estimates of the supplementary parameters across countries. By setting $\gamma$ to be a vector, typical inferences regarding linear restrictions of its components (such as equality to 
prespecified values, constancy across groups, etc.) can be tested using the standard Wald-test method, because the variance matrix of the estimate of $\gamma$ can be computed after the model fit. ${ }^{3}$ With this approach, we can assess country-level variation directly from the results of the multigroup analysis, without having to resort to multilevel models that require the assumption of randomness across countries. In applications with a small number of well-identified countries, associating the countries with randomness is unnatural.

In the empirical analysis, we will also use the SPA to make inferences on the correlation of country-level parameters (such as mean profitability or persistence index) with other countrylevel variables. Note that SPA is just rooted on functions of parameters that are evaluated at the parameter estimates and whose variability is assessed using the delta method or other related procedures for finding the variance of transformed statistics. ${ }^{4}$ Nowadays, most current SEM software has provision for estimating such (typically nonlinear) functions of parameters of the model. Although novel for assessing variation across-groups, the SPA is not novel in general SEM analysis. ${ }^{5}$ The methods described here have long been used to assess mediating effects or other transformation parameters. See, for example, Cheung (2007a) in estimating mediating effects and McArdle and Hamagami (1996) for estimating effect-code coefficients. In the case of SEM software with no provision for transformation parameters, simple functions could be evaluated using "phantom variables" (see Loehlin, 2004; Rindskopf, 1984), a line of approach, however, that is of declining relevance given the current developments of software. ${ }^{6}$

\section{Indices of Persistence (IP)}

To compare persistence across countries, we define a single parameter that represents the overall persistence of the system. Because the variance of $U_{t}$ may vary widely across countries due to circumstances unrelated to profits (for example, countries may have different variances of the measurement error, a component of $U_{t}$ ), the indices introduced below are computed after subtracting the residual terms $U_{t}$ from profits. We assume that there is variation beyond $U_{t}$, so $\operatorname{Var}(A)+\operatorname{Var}(P) \neq 0$. The following index of persistence (IP) is defined:

$$
\mathrm{IP}=\frac{\operatorname{Var}(P)+\beta \operatorname{Var}(A)}{\operatorname{Var}(P)+\operatorname{Var}(A)} .
$$

This index integrates both the value of $\beta$ and the values of the variances of the permanent and transitory components of the model and is free of the residual terms $U_{t}$. It varies from 0 (no persistence) to 1 (complete persistence), where complete persistence means that all profit differences are permanent. The maximum value of 1 can be reached when $\beta=1$ (implausible, because we assume stationarity) or when $\operatorname{Var}(A)=0$ (no transitory component in the model). The minimum value 0 requires that $\operatorname{Var}(P)+\beta \operatorname{Var}(A)=0$, attained when both $\operatorname{Var}(P)$ and $\beta$ are zero.

The IP defined by Equation 5 differs from the index of persistence IP* computed using autorregressive models (e.g., Mueller, 1986, 1990). In our notation,

$$
\mathrm{IP}^{*}=\frac{\operatorname{Var}(P)+\beta \operatorname{Var}(A)}{\operatorname{Var}(P)+\operatorname{Var}(A)+\overline{\operatorname{Var}(U)}},
$$

where $\overline{\operatorname{Var}(U)}$ denotes the average of the variances $\operatorname{Var}\left(U_{t}\right)$. It holds that

$$
\mathrm{IP}^{*}=\frac{\mathrm{IP}}{1+\mathrm{IP} \times H}
$$

where $H=\frac{\overline{\operatorname{Var}(U)}}{\operatorname{Var}(P)+\beta \operatorname{Var}(A)}$, so IP $\leq \mathrm{IP}$, with IP $=\mathrm{IP}^{*}$ only when $\overline{\operatorname{Var}(U)}=0$. 
Table 3. Distribution of Firms by Country and Year and Number of Industries

\begin{tabular}{|c|c|c|c|c|c|c|c|}
\hline \multirow[b]{2}{*}{ Country } & \multirow[b]{2}{*}{ Firms } & \multirow[b]{2}{*}{ Industries } & \multicolumn{5}{|c|}{ Year } \\
\hline & & & 1999 & 2000 & 2001 & 2002 & 2003 \\
\hline Austria & 697 & 200 & 320 & 300 & 367 & 658 & 436 \\
\hline Belgium & 7,467 & 370 & 6,177 & 6,841 & 7,063 & 7,256 & 7,137 \\
\hline Denmark & 2,975 & 276 & 1,824 & 2,538 & 2,703 & 2,825 & 2,853 \\
\hline Finland & 2,062 & 287 & 1,556 & 1,799 & 1,924 & 2,009 & 1,995 \\
\hline France & 21,739 & 398 & 17,844 & 19,209 & $|9,93|$ & 20,894 & 19,168 \\
\hline Germany & 4,959 & 363 & 1,972 & 2,122 & 3,263 & 4,801 & 2,970 \\
\hline Greece & 2,345 & 273 & 1,895 & 2,134 & 2,231 & 2,295 & 2,324 \\
\hline Ireland & 484 & 146 & 402 & 454 & 435 & 404 & 350 \\
\hline Italy & 12,832 & 392 & 10,055 & 10,662 & 11,122 & 12,519 & 10,265 \\
\hline Luxemburg & 204 & 91 & 85 & 85 & 155 & 159 & 79 \\
\hline Netherlands & 3,875 & 312 & 2,116 & 2,074 & 2,446 & 3,369 & 2,352 \\
\hline Portugal & 2,284 & 287 & I,705 & 1,820 & 1,967 & 2,237 & $|, 74|$ \\
\hline Spain & 12,317 & 391 & 10,222 & 10,856 & 11,599 & 12,057 & 10,042 \\
\hline Sweden & 5,140 & 342 & 3,966 & 4,601 & 4,811 & 4,976 & 5,057 \\
\hline United Kingdom & 25,457 & 412 & 16,532 & 19,956 & 21,693 & 23,113 & 22,497 \\
\hline Total & 104,837 & 427 & 76,67I & 85,451 & 91,710 & 99,572 & 89,266 \\
\hline
\end{tabular}

\section{Database: Countries and Variables}

We use the European database, Amadeus, from Bureau van Dijk (2005) ${ }^{7}$ that provides accounting data from 15 EU countries recorded over a 5-year period, from 1999 to 2003 . This period begins with currency unification in January 1999 and ends with EU enlargement to 25 countries in May 2004.

The complete Amadeus Top 250,000 database contains information about 243,665 large companies of all sectors of the economy from 1996 to 2004 belonging to 39 European countries. ${ }^{8}$ In the analysis, we use only the data on firms of the EU-15 that report unconsolidated accounts; this reduces the number of firms to 104,837 .

Table 3 lists the number of firms and 4-digit industries by year in the 15 EU member countries in the period of study. Mean profit rates over the 5 years differ among countries, as shown in Table 4 .

We also consider the classification of firms by economic sectors defined by the first digit Standard Industrial Classification (SIC) code. ${ }^{9}$ Table 5 is the corresponding contingency table. Of relevance here is the potential association among the rows and columns of the table and the potential also for confounding when assessing country versus industry effects on basic parameters of the model.

Database entries are missing for some firms in some years for one of several reasons: a firm may be founded or dissolved (by bankruptcy, merger, or the like) during the period studied; it may change its status or location (registration) from one country to another; or, simply, the firm does not report its accounts in a specific year. Table 6 shows information on the pattern of missingness in the database. It shows that of the 104,837 firms, 59.4\% have complete records for all the years. Of the remaining firms, about half are "Drop in" (i.e., late entrants); that is, firms that enter the panel after the observation period starts but remain until the end. These are patterns 3 to 6 . Of the remaining $20 \%$, about half, $9.5 \%$, are "Drop out" (i.e., early exiters); that is, firms that enter the panel in the 1 st year of the observation period but exit before the end. The remaining $10 \%$ of firms in the panel have one of the numerous other patterns. We could analyze the four types of firms as different groups. Such an approach would protect the inferences from possible selection biases due to missingness as far as the assumption of missing at random (MAR) holds. In the theory of missing data, MAR assumes that conditional on the observed data, patterns of missingness are independent of the 
Table 4. Mean Profit Rates Over the 5 Years

\begin{tabular}{|c|c|c|c|c|c|c|}
\hline \multirow[b]{2}{*}{ Country } & \multicolumn{5}{|c|}{ Year } & \multirow[b]{2}{*}{ Mean } \\
\hline & 1999 & 2000 & 2001 & 2002 & 2003 & \\
\hline Austria & 6.65 & 7.04 & 5.26 & 3.06 & 5.59 & 5.44 \\
\hline Belgium & 4.09 & 4.08 & 3.69 & 3.56 & 4.15 & 5.06 \\
\hline Denmark & 5.36 & 4.76 & 4.05 & 2.55 & 3.68 & 3.25 \\
\hline Finland & 9.30 & 6.16 & 8.02 & 8.17 & 8.78 & 8.82 \\
\hline France & 4.65 & 4.7I & 4.37 & 4.50 & 4.81 & 4.97 \\
\hline Germany & 8.08 & 8.19 & 5.47 & 4.99 & 5.92 & 6.14 \\
\hline Greece & 7.60 & 6.57 & 5.79 & 5.24 & 5.28 & 5.97 \\
\hline Ireland & 7.55 & 6.02 & 5.92 & 7.39 & 8.43 & 6.97 \\
\hline Italy & 4.25 & 3.71 & 3.57 & 3.41 & 3.17 & 3.78 \\
\hline Luxemburg & 7.86 & 6.60 & 5.99 & 7.31 & 6.91 & 6.99 \\
\hline Netherlands & 6.73 & 6.52 & 6.21 & 5.74 & 6.75 & 7.05 \\
\hline Portugal & 3.78 & 3.65 & 3.36 & 3.18 & $3.4 I$ & 3.61 \\
\hline Spain & 5.66 & 5.23 & 4.83 & 4.75 & 5.89 & 5.47 \\
\hline Sweden & 5.66 & 7.66 & 4.73 & 5.41 & 6.68 & 6.20 \\
\hline United Kingdom & 4.46 & 4.48 & 3.69 & 3.81 & 7.27 & 5.00 \\
\hline All countries & 5.46 & 5.09 & 4.45 & 4.31 & 5.85 & 5.12 \\
\hline
\end{tabular}

Table 5. Number of Firms by Country and Sector

\begin{tabular}{lrrrrrrrr}
\hline & \multicolumn{7}{c}{ Types of industry } \\
\cline { 2 - 9 } Country & A & \multicolumn{1}{c}{ B } & \multicolumn{1}{c}{ C } & \multicolumn{1}{c}{ D } & \multicolumn{1}{c}{ E } & \multicolumn{1}{c}{ FG } & \multicolumn{1}{c}{ H } & \multicolumn{1}{c}{ I } \\
\hline Austria & 0 & 3 & 61 & 256 & 54 & 222 & 59 & 42 \\
Belgium & 26 & 30 & 364 & 1,711 & 679 & 2,447 & 1,211 & 999 \\
Germany & 12 & 25 & 181 & 1,422 & 736 & 1,091 & 721 & 771 \\
Denmark & 28 & 10 & 111 & 516 & 311 & 742 & 956 & 301 \\
Finland & 2 & 8 & 93 & 529 & 254 & 657 & 307 & 212 \\
France & 93 & 108 & 871 & 5,291 & 1,480 & 7,280 & 3,970 & 2,646 \\
Greece & 68 & 33 & 114 & 793 & 135 & 798 & 168 & 236 \\
Italy & 148 & 49 & 712 & 5,077 & 1,033 & 4,124 & 349 & 1,340 \\
Netherlands & 24 & 52 & 193 & 645 & 336 & 915 & 1,185 & 525 \\
Portugal & 23 & 10 & 212 & 733 & 187 & 727 & 189 & 203 \\
Spain & 123 & 55 & 874 & 2,929 & 978 & 3,484 & 2,119 & 1,755 \\
Sweden & 33 & 12 & 192 & 1,194 & 531 & 1,544 & 976 & 658 \\
Ireland & 3 & 1 & 40 & 150 & 30 & 143 & 61 & 56 \\
Luxembourg & 0 & 2 & 21 & 47 & 14 & 63 & 42 & 15 \\
United Kingdom & 121 & 318 & 1,398 & 4,686 & 1,857 & 4,567 & 6,193 & 6,317 \\
Total & 704 & 716 & 5,437 & 25,979 & 8,615 & 28,804 & 18,506 & 16,076 \\
\hline & & & & & & & &
\end{tabular}

unobserved data (Rubin, 1976). The analysis described below is based on full information maximum likelihood (ML) with missing data. It could be formalized as multigroup SEM with groups defined by the pattern of missingness. MAR, as an untestable assumption, is always questionable, but it is certainly less stringent than the missing completely at random (MCAR) implicit in pairwise and listwise deletion methods. See Cheung (2007b) for methods for handling missing data in longitudinal SEM analysis under the MCAR assumption. 
Table 6. Information on Missing Data Patterns in the Database ( 0 Indicates Missing)

\begin{tabular}{|c|c|c|c|c|c|c|c|c|c|}
\hline \multirow[b]{2}{*}{ Pattern } & \multirow[b]{2}{*}{ \# of firms } & \multirow[b]{2}{*}{$\%$} & \multirow[b]{2}{*}{ Cumulative \% } & \multicolumn{5}{|c|}{ Years } & \multirow[b]{2}{*}{ Type } \\
\hline & & & & 1999 & 2000 & 2001 & 2002 & 2003 & \\
\hline I & 62,280 & 59.4 & 59.4 & 1 & 1 & I & I & 1 & Complete \\
\hline 2 & 9,024 & 8.6 & 68.0 & I & 1 & 1 & I & 0 & Drop out \\
\hline 3 & 9,021 & 8.6 & 76.6 & 0 & 1 & 1 & I & I & Drop in \\
\hline 4 & 5,672 & 5.4 & 82.0 & 0 & 0 & 0 & I & 1 & Drop in \\
\hline 5 & 4,802 & 4.6 & 86.6 & 0 & 0 & 1 & I & I & Drop in \\
\hline 6 & 2,827 & 2.7 & 89.3 & 0 & 0 & 0 & 0 & 1 & Drop in \\
\hline 7 & 2,190 & 2.1 & 91.4 & 0 & I & I & 0 & 0 & Other \\
\hline 8 & 1,586 & 1.5 & 92.9 & 1 & 1 & 0 & I & 1 & \\
\hline 9 & I, 187 & 1.1 & 94.0 & 0 & I & 1 & I & 0 & \\
\hline 10 & 1,083 & 1.0 & 95.1 & 0 & 0 & 0 & I & 0 & \\
\hline II & 938 & 0.9 & 96.0 & 1 & 0 & 1 & I & 1 & \\
\hline 12 & 620 & 0.6 & 96.6 & 1 & I & 1 & 0 & 1 & \\
\hline 13 & 572 & 0.5 & 97.1 & 1 & 1 & 1 & 0 & 0 & \\
\hline 14 & 500 & 0.5 & 97.6 & I & 0 & I & I & 0 & \\
\hline 15 & 364 & 0.3 & 97.9 & I & 0 & 0 & I & 1 & \\
\hline 16 & 304 & 0.3 & 98.2 & 1 & 1 & 0 & I & 0 & \\
\hline 17 & 256 & 0.2 & 98.5 & 1 & 1 & 0 & 0 & 0 & \\
\hline 18 & 255 & 0.2 & 98.7 & 1 & 0 & 0 & 0 & 0 & \\
\hline 19 & 220 & 0.2 & 98.9 & 0 & I & 0 & I & I & \\
\hline 20 & 154 & 0.1 & 99.1 & 0 & 0 & 1 & 0 & 0 & \\
\hline 21 & 134 & 0.1 & 99.2 & 0 & 1 & 1 & 0 & 0 & \\
\hline 22 & 125 & 0.1 & 99.3 & 1 & I & 0 & 0 & 1 & \\
\hline 23 & 124 & 0.1 & 99.4 & 1 & 0 & 0 & I & 0 & \\
\hline 24 & 115 & 0.1 & 99.5 & 0 & 1 & 0 & 0 & 0 & \\
\hline 25 & 105 & 0.1 & 99.6 & 0 & 0 & 1 & 0 & 1 & \\
\hline 26 & 100 & 0.1 & 99.7 & 0 & 1 & 1 & 0 & 1 & \\
\hline 27 & 79 & 0.1 & 99.8 & 1 & 0 & 0 & 0 & 1 & \\
\hline 28 & 67 & 0.1 & 99.9 & 0 & I & 0 & I & 0 & \\
\hline 29 & 50 & $<0.1$ & 99.9 & 0 & 1 & 0 & 0 & 1 & \\
\hline 30 & 45 & $<0.1$ & 100.0 & 1 & 0 & 1 & 0 & 0 & \\
\hline 31 & 38 & $<0.1$ & 100.0 & I & 0 & 1 & 0 & 1 & \\
\hline
\end{tabular}

\section{Variables and Estimation}

Following previous studies (McGahan \& Porter, 1999, 2002; Wiggings \& Ruefli, 2002), we use the ROA as a performance measure. ROA is defined as the ratio of annual profits (or losses) before taxes to total assets. As with other accounting measures of firm performance, ROA presents some difficulties when it is used in an analysis of several countries (Hult et al., 2008). Observed differences in the ROA may reflect differences not only in profitability but also in taxation rules and in the accounting practices used to generate the financial statements, such as methods to account for depreciation, to consolidate accounts, to account for transaction and translation of gains and losses in foreign currencies, to use reserve funds, and so on (Blaine, 1994). Observed differences in the ROA may also reveal differences in the institutional (i.e., legal, economic, political, and cultural) context in which firms operate (Choi et al., 1983; Krisement, 1997; Nobes \& Parker, 2006).

Although we cannot adjust the performance measures for these distortions, we have tried to minimize these effects in our research. To achieve control over some of these issues, we have adjusted our measure of the ROA by using profit/losses before taxes to avoid the influence of tax rates (Christmann, Gray, \& Yip, 1999). Moreover, economic and political integration in Europe has 
Table 7. $\chi^{2}$ Goodness-of-Fit Statistics for the Models

\begin{tabular}{lrcr}
\hline Model & \multicolumn{1}{c}{$\chi^{2}$} & $d f$ & $p$ value \\
\hline SG & 4.88 & 12 & .96 \\
MG & 253.67 & 182 & .00 \\
MGI & 293.01 & 196 & .00 \\
MG2 & 251.45 & 196 & .00 \\
MG3 & $5,379.95$ & 218 & .00 \\
\hline
\end{tabular}

Note: $M G=$ multigroup.

Table 8. $\chi^{2}$ Difference Tests for Sets of Restrictions

\begin{tabular}{llcrr}
\hline Nested models & Test (for equality of) & $\chi^{2}$ difference test $^{\mathrm{a}}$ & $d f$ & $p$ value \\
\hline MGI versus MG & Means & 103.32 & 14 & .000 \\
MG2 versus MG & Persistence parameter $\beta$ & 18.18 & 14 & .200 \\
MG3 versus MG & Variances & $2,954.59$ & 36 & .000
\end{tabular}

Note: $M G=$ multigroup.

${ }^{a}$ Tests based on scaled difference tests.

promoted the harmonization of accounting laws (Cañibano \& Mora, 2000) and the homogenization of the national institutional context of its members. European countries are thus an appropriate peer group to assess company differences in profitability as the accounting methods and the social and financial systems in which firms operate are so similar.

The analysis was carried out using the Mplus 5.2 (Muthén \& Muthén, 2007) SEM software. We use full information ML for missing data. The model and estimation approach could be framed within Satorra's (2002) multigroup analysis. To protect against possible dependence of observations due to firms being nested within industries (as well as possible nonnormality), standard errors, $\chi^{2}$ goodness-of-fit tests, and difference of $\chi^{2}$ test are based on the aggregate approach using the corresponding adjusting factors (see Muthén \& Satorra, 1995). For technical details of the model, see Bou and Satorra (2007, Appendix).

\section{Results}

Table 7 lists $\chi^{2}$ statistics for several model fits to the data. The naive approach of not contemplating any differences among the countries, thus pooling the data of all countries into a single group analysis, corresponds to the SG model of Table 2 and to the $\chi^{2}$ of the first row in Table 7 . We see that the model fits the data according to the $\chi^{2}$ goodness-of-fit test $\left(\chi^{2}=4.88, d f=12, p=.96\right) .{ }^{10}$ The goodness-of-fit test for the single-group analysis cannot detect possible differences across groups of parameters of the model, so a single-group analysis (with a common set of means) does not disclose cross-country differences of fundamental issues of firm profitability. To analyze these differences, we require the specification of models that incorporate parameters specific to each country. The following subsection shows the results of the multigroup models that account for these differences.

\section{Country Differences}

Tables 7 and 8 list the $\chi^{2}$ values for tests on several nested models. Models MG1 to MG3 are submodels of MG, so a $\chi^{2}$ difference test is used to assess the validity of the restrictions that MG1 to 
MG3 impose on MG. Unlike the sequence of the hierarchical nested model approach frequently used to assess invariance across groups (e.g., Ployhart \& Oswald, 2004; Vandenberg \& Lance, 2000), we adopt the approach of comparing only MG1-MG3 with MG because we want to assess cross-country invariance of specific parameters (rather than finding the model that best fits the data).

The $\chi^{2}$ statistic for the baseline model MG is 253.67 , associated with $182 d f$. The parameter estimates and their estimated standard errors are listed in Table $9 .{ }^{11} \mathrm{We}$ observe that nine countries have a permanent component (Belgium, Finland, Greece, Ireland, Italy, Netherlands, Spain, Sweden, and the United Kingdom), which is only significantly different from zero in Belgium, Italy, and Spain. There is also substantial variation across countries in the variances of the components of profitability (i.e., $\operatorname{Var}(P), \operatorname{Var}(A)$, and $\operatorname{Var}(U)$ ). With the $\mathrm{MG}$ approach, we also estimate parameters that allow us to assess cross-country differences in mean level of profitability. The last column of Table 9 shows that the country-mean varies across countries from 3.52 in Portugal to 8.67 in Finland.

To assess the significance of parameter differences across countries, the fit of the restricted models MG1-MG3 is compared to the fit of the general model MG. The model MG1 is used to assess the homogeneity of means across groups. The $\chi^{2}$ goodness-of-fit statistic for the less restricted model MG1 is equal to 293.01 and is associated with $196 d f(p=.00)$. The $\chi^{2}$ statistic for the test of MG1 against MG is reported in the first row of Table 8 , obtaining a $\chi^{2}=103.32$ with $d f=14$ $(=196-182){ }^{12}$ The test statistic is much greater than the $d f$, so we reject the null hypothesis of equality across countries of the (mean) level of profitability.

MG2 imposes equality across groups of the autoregressive parameters $\beta$, with all the other parameters allowed to be country specific. The fit of this model is $\chi^{2}=251.45, d f=196(p=.00)$. The $\chi^{2}$ difference test of MG2 against MG (see Table 8 ) gives $\chi^{2}=18.18, d f=14, p=.20$; so, a 5\%level test does not reject the hypothesis of equality across groups of the autoregressive parameters $\beta$.

In MG3, the variances of the permanent and transitory components are equal for those countries that have both components. ${ }^{13}$ The $\chi^{2}$ goodness of fit for this model is $\chi^{2}=5,379.95, d f=218, p$ value far below the $5 \%$ significance level, thus indicating a poor fit of the model. The scaled difference $\chi^{2}$ test of MG3 against MG is $\chi^{2}=2,954.59, d f=36$, which also rejects the null hypothesis of equality of variances (homoscedasticity) across groups. Rejection is not surprising when the large differences in variances among several countries reported in Table 9 are noted; for example, $\operatorname{Var}(A)$ for the United Kingdom is 9, 433.06 (standard error 4,617.24) and for Italy, 74.21 (standard error 11.93).

From the estimates reported in Table 9, we compute the variance decomposition shown on the lefthand side of Table 10. The last row of the table shows the same variance decomposition for the average across countries, with percentages of permanent, transitory, and unexplained components of $12 \%$, $43 \%$, and $45 \%$, respectively. The transitory and unexplained components are about four times greater than the permanent component, indicating that within the EU-15, firms' profit differences are mainly transitory and idiosyncratic. The variance decomposition varies widely across the countries. For Austria, Denmark, France, Germany, Luxemburg, and Portugal, the permanent component is estimated to be zero (i.e., there is a zero in the corresponding cell), whereas for Greece and Finland, the permanent component is substantially high. When comparing the variance decomposition across countries, we should take into account that the reported percentages are estimates, subject to sampling fluctuation. This raises some difficulty in interpreting such estimates; for example, for Finland, which has high values of standard errors of estimates of variance parameters (see the corresponding row of Table 9), we are unsure on how stable the dominant value of the permanent component is. A more precise comparison of the profitability across countries can be achieved using the IP that are reported in the same table, with their corresponding standard errors, and that are discussed in the following section.

The last column of Table 10 reports the estimates and standard errors of the effect-code (McArdle \& Hamagami, 1996) for each country, that is, deviations with respect to the overall mean. The sign of the estimated effect-code indicates profitability of the country above (below) the grand mean. Seven of the 15 countries (Finland, Germany, Greece, Ireland, Netherlands, Luxembourg, and 


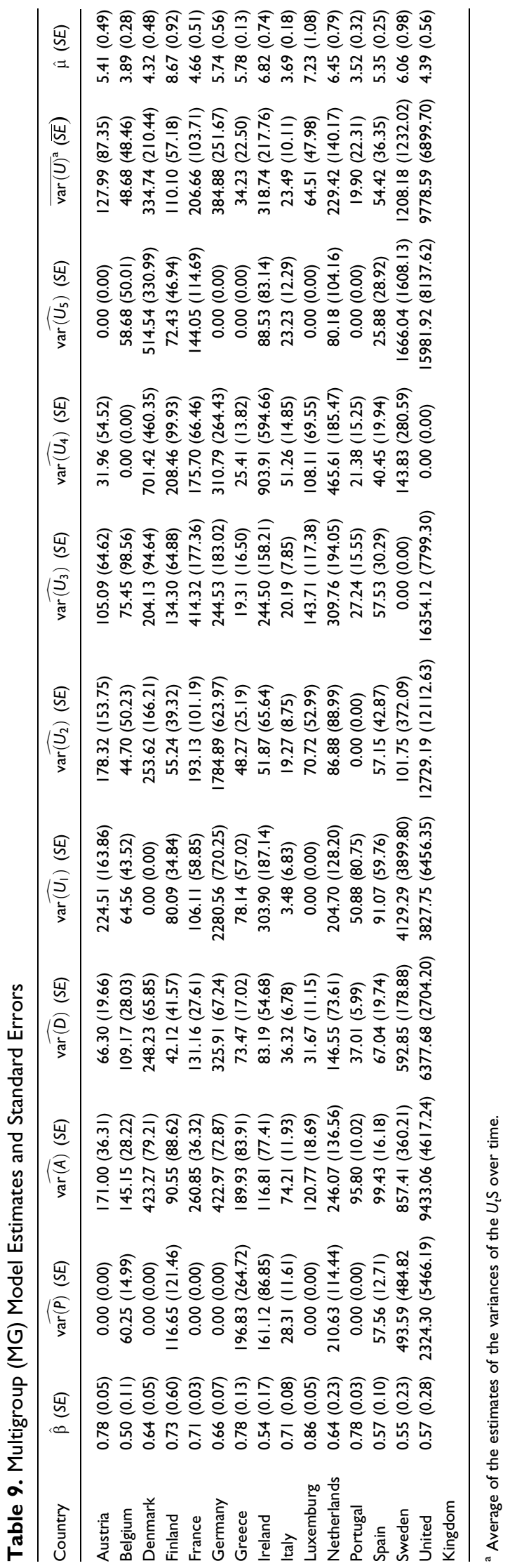


Table 10. Variance Decomposition of Profitability, Estimates of the IPs, and Country-mean Profitability in Deviations From Overall Mean Profitability ${ }^{\mathrm{a}}$

\begin{tabular}{|c|c|c|c|c|c|}
\hline \multirow[b]{2}{*}{ Country } & \multicolumn{3}{|c|}{$\%$ of variance } & \multirow{2}{*}{$\begin{array}{l}\text { Persistence } \\
\quad \text { IP }\end{array}$} & \multirow{2}{*}{$\begin{array}{c}\text { Deviations }^{\mathrm{b}} \\
\mu_{g}-\overline{\mu_{g}}\end{array}$} \\
\hline & $P$ & $A_{t}$ & $U_{t}$ & & \\
\hline Austria & 0 & 57 & 43 & $0.78(0.04)$ & $-0.07(0.50)$ \\
\hline Belgium & 24 & 57 & 19 & $0.65(0.06)$ & $-1.59(0.24)^{c}$ \\
\hline Denmark & 0 & 56 & 44 & $0.64(0.04)$ & $-1.17(0.37)^{c}$ \\
\hline Finland & 37 & 28 & 35 & $0.88(0.18)$ & $3.18(0.78)^{\mathrm{c}}$ \\
\hline France & 0 & 56 & 44 & $0.70(0.03)$ & $-0.83(0.33)^{c}$ \\
\hline Germany & 0 & 52 & 48 & $0.66(0.07)$ & $0.26(0.58)$ \\
\hline Greece & 47 & 45 & 8 & $0.89(0.07)$ & $0.56(0.65)$ \\
\hline Ireland & 28 & 20 & 52 & $0.80(0.10)$ & I.37 (0.7I) \\
\hline Italy & 22 & 59 & 17 & $0.79(0.04)$ & $-1.79(0.29)^{c}$ \\
\hline Luxemburg & 0 & 65 & 35 & $0.86(0.04)$ & $1.72(0.95)$ \\
\hline Netherlands & 31 & 36 & 33 & $0.80(0.08)$ & $0.96(0.73)$ \\
\hline Portugal & 0 & 83 & 17 & $0.78(0.03)$ & $-1.97(0.3 \mathrm{I})^{\mathrm{c}}$ \\
\hline Spain & 27 & 47 & 26 & $0.72(0.06)$ & $-0.14(0.28)$ \\
\hline Sweden & 19 & 33 & 47 & $0.72(0.12)$ & $0.59(0.78)$ \\
\hline United Kingdom & II & 45 & 44 & $0.65(0.13)$ & $-1.09(0.48)^{c}$ \\
\hline Average & 12 & 43 & 45 & $0.76(0.02)$ & $0.00(--)$ \\
\hline
\end{tabular}

a Standard errors are shown in parentheses.

${ }^{b}$ Deviations from the overall mean profitability level.

c Significant at the $5 \%$ level.

Sweden) emerge with positive effect-code values, that is higher profitability than the overall mean, whereas the other countries (Austria, Belgium, Denmark, France, Italy, Portugal, Spain, and the United Kingdom) have negative effect-code values. Seven of the 15 countries show significant differences from the overall mean. Firms in Belgium, Denmark, France, Italy, Portugal, and the United Kingdom have statistically significant lower profitability than the overall mean, whereas the mean profitability rate in Finland is significantly higher than the overall mean. Based on these results, we conclude that there is a substantial level of variation in the mean profitability rate across EU countries.

\section{Results for IP}

The persistence for a country is characterized by the index IP defined in Formula 5. Note that this index is a group-specific supplementary parameter (defined after the fit of the model). The estimates of IP for each country are shown in Table 10. The standard errors of the estimates of these derived parameters are also provided in the table.

Across the EU-15 countries, IP ranges from the smallest value of 0.64 for Denmark, to the largest value of 0.89 for Greece; hence, we observe a narrow range of variation of this index. The standard errors are quite small, which indicates high precision in estimating the value of the IP for each country, except for Finland, which has an extreme standard error (0.18) and, to a lesser degree, for the United Kingdom, Sweden, and Ireland, with respective values of $0.13,0.12$, and 0.10 . The standard errors of the estimates of IP are needed if we want to construct a $95 \%$ confidence interval of the IP for each country. Table 10 shows that for several pairs of countries, the $95 \%$ confidence intervals of the IP do not overlap, attesting the existence of significant differences in persistence among the 
EU-15 countries. We also conduct a Wald test for the hypothesis of equality of IPs across countries; the $\chi^{2}$ value is $42.65(d f=14, p<.05)$, a value that rejects the null hypothesis.

\section{Country and Industry Effects}

The analysis has so far assumed homogeneity across industries both within each country and on the overall set of countries. This hypothesis may not always hold because industries could also differ in persistence, with the variation across industries being confounded possibly with the variation across countries. ${ }^{14}$ Previous studies in variance decomposition attest to difference across sectors (types of industries) when considering the magnitude of firm, industry, and country effects. For example, McGahan and Porter (1997) and Hough (2006) compared the components of variance of manufacturing firms with other sectors of economy and found a smaller industry effect in manufacturing. In the same vein, McGahan and Porter (2002) also found higher rates of persistence in manufacturers than in other sectors. These results suggest the importance of sectoral analyses to investigate how much variation is due to firms, industries, and countries and to what extent differences across countries may in fact be due to a particular configuration of industries in a given country. Table 5 shows the number of firms classified by sectors, where the sectors were defined using the first-digit SIC (this definition of sectors follows previous studies; e.g., Hough, 2006; McGahan \& Porter, 1997, 2002).

The classical $\chi^{2}$ test for independence for rows and columns of a contingency table can be applied to investigate the hypothesis of no particular configuration of industries across countries. Table 5 shows the frequency of firms cross-classified by country and sector. For this table, we obtain a $\chi^{2}=10,243.45$, with $d f=98\left(p<2.2 \times 10^{-16}\right)$, which clearly rejects the null hypothesis of independence between countries and sectors. That is, certain countries tend to have a particular configuration of industries. Cramer's V for Table 5 is 0.30 , thus indicating a substantial association between rows and columns. Such high association between countries and sectors will induce overlap (confounding) when assessing the separate effects of country and sector on model parameters.

We now consider the multigroup analysis of the basic model defined in Section 2 with groups defined on the basis of the cross-classification of countries and sectors of Table 5. To ensure a large enough sample size in each group, Agriculture (A), Mining (B), and Construction (C) were merged into a single sector, and Luxemburg was excluded from the analysis due to the small number of firms in this country. Tables 11 and 12 report the estimates (and corresponding standard errors) for the average level of profitability $\left(\mu_{g}\right)$ and the IP. These tables give detailed information of the model fit in each group as well as information on the variation both across country and sectors. ${ }^{15,16}$

Table 11 shows substantial variation between groups in the overall mean profitability $\mu$. For example, sector I in Finland has a profitability of almost 13\%, whereas sector E in Sweden has just an average profitability value of 0.26 . With some exceptions, standard errors are relatively small, attesting to high precision when estimating mean profitability in each of the country/sector groups. Table 12 also shows variation in IPs across countries, with values ranging from 0.21 for sector $\mathrm{H}$ in Germany to 0.99 for sector $\mathrm{E}$ in Greece and sector $\mathrm{H}$ in Ireland.

Tables 11 and 12 show also row and column summary measures of mean level and variance. ${ }^{17}$ Table 11 shows that Finland has the highest average profitability (8.65), whereas Portugal and Italy have the lowest (3.00 and 3.22, respectively). Sector FG has the highest average profitability (6.68), whereas sectors $\mathrm{H}$ and $\mathrm{E}$ have the lowest profitability (3.12 and 3.39, respectively). Even though sectors $\mathrm{E}$ and $\mathrm{H}$ have similar low average profitability, the standard error of sector $\mathrm{E}$ is much larger than that of sector $\mathrm{H}$, so there is more uncertainty in our data regarding estimates of the level of profitability in sector E. The $S D$ of the row summary and the column summary gives the variation of the mean profitability across sectors and countries, respectively. Our results suggest that mean 


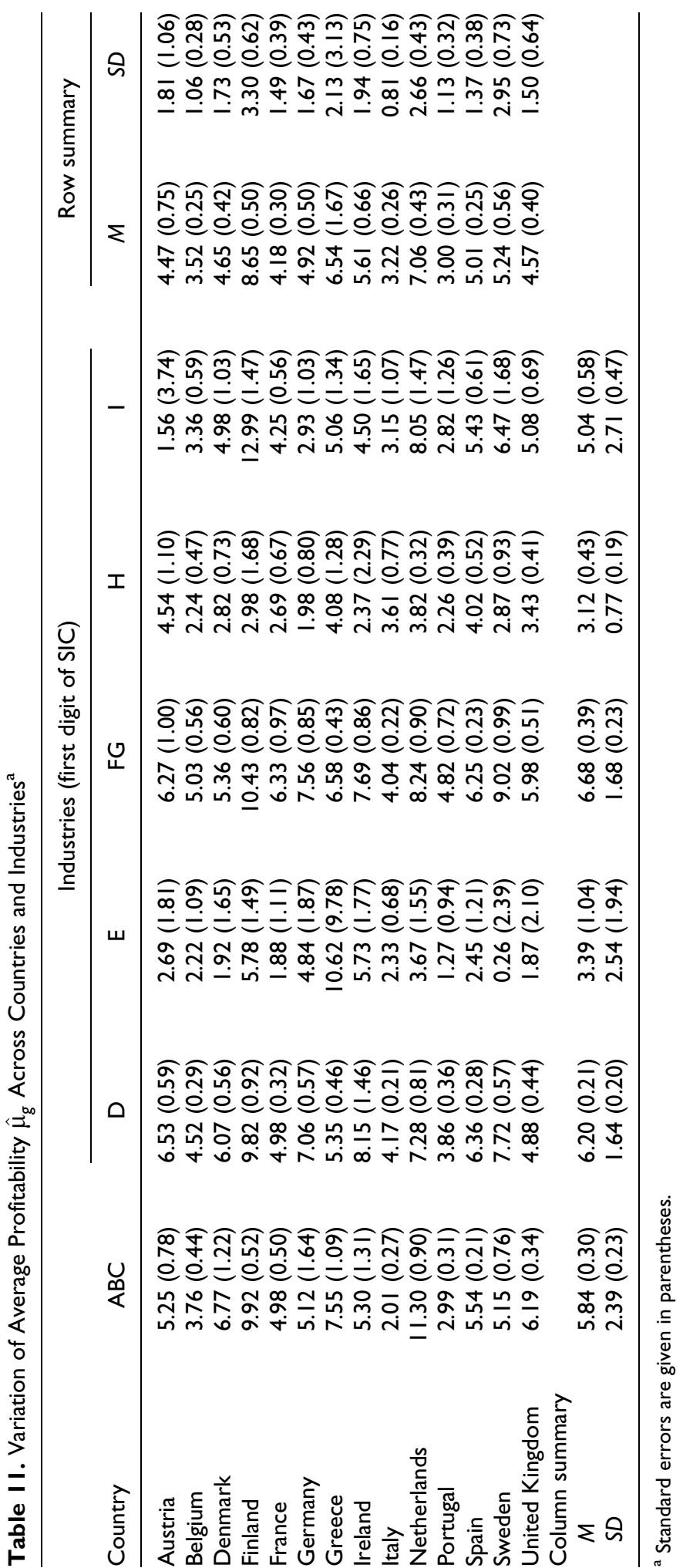


Table I 2. Variation of Indices of Persistence (IP) Across Countries and Industries ${ }^{\mathrm{a}}$

\begin{tabular}{|c|c|c|c|c|c|c|c|c|}
\hline \multirow[b]{2}{*}{ Country } & \multirow[b]{2}{*}{$A B C$} & \multicolumn{5}{|c|}{ Industries (first digit of SIC) } & \multicolumn{2}{|c|}{ Row summary } \\
\hline & & $\mathrm{D}$ & $E$ & FG & $\mathrm{H}$ & I & M & $S D$ \\
\hline Austria & $0.86(0.10)$ & $0.85(0.06)$ & $0.96(0.03)$ & $0.80(0.02)$ & $0.86(0.07)$ & $0.94(0.05)$ & $0.88(0.02)$ & $0.06(0.02)$ \\
\hline Belgium & $0.76(0.04)$ & $0.77(0.02)$ & $0.78(0.04)$ & $0.80(0.04)$ & $0.77(0.10)$ & $0.70(0.05)$ & $0.76(0.02)$ & $0.03(0.02)$ \\
\hline Denmark & $0.84(0.10)$ & $0.74(0.03)$ & $0.63(0.06)$ & $0.74(0.04)$ & $0.5 I(0.07)$ & $0.77(0.06)$ & $0.7 \mathrm{I}(0.03)$ & $0.11(0.03)$ \\
\hline Finland & $0.71(0.11)$ & $0.89(0.05)$ & $0.97(0.04)$ & $0.81(0.03)$ & $0.88(0.13)$ & $0.96(0.03)$ & $0.87(0.03)$ & $0.09(0.03)$ \\
\hline France & $0.85(0.03)$ & $0.71(0.03)$ & $0.74(0.02)$ & $0.77(0.03)$ & $0.68(0.09)$ & $0.64(0.04)$ & $0.73(0.02)$ & $0.07(0.02)$ \\
\hline Germany & $0.84(0.09)$ & $0.59(0.09)$ & $0.84(0.10)$ & $0.90(0.06)$ & $0.21(0.06)$ & $0.73(0.09)$ & $0.69(0.03)$ & $0.11(0.01)$ \\
\hline Greece & $0.79(0.03)$ & $0.83(0.04)$ & $0.99(0.01)$ & $0.84(0.02)$ & $0.50(0.05)$ & $0.76(0.03)$ & $0.79(0.01)$ & $0.15(0.02)$ \\
\hline Ireland & $0.83(0.03)$ & $0.87(0.06)$ & $0.44(0.06)$ & $0.87(0.16)$ & $0.99(0.08)$ & $0.71(0.08)$ & $0.78(0.04)$ & $0.17(0.03)$ \\
\hline Italy & $0.88(0.06)$ & $0.79(0.02)$ & $0.85(0.04)$ & $0.85(0.02)$ & $0.91(0.17)$ & $0.86(0.05)$ & $0.85(0.03)$ & $0.04(0.04)$ \\
\hline Netherlands & $0.90(0.03)$ & $0.85(0.05)$ & $0.82(0.08)$ & $0.83(0.03)$ & $0.93(0.09)$ & $0.80(0.07)$ & $0.86(0.02)$ & $0.05(0.03)$ \\
\hline Portugal & $0.71(0.06)$ & $0.81(0.02)$ & $0.90(0.03)$ & $0.85(0.03)$ & $0.72(0.08)$ & $0.79(0.06)$ & $0.80(0.02)$ & $0.07(0.02)$ \\
\hline Spain & $0.79(0.05)$ & $0.81(0.02)$ & $0.87(0.04)$ & $0.78(0.0 \mathrm{I})$ & $0.83(0.05)$ & $0.82(0.04)$ & $0.82(0.01)$ & $0.03(0.01)$ \\
\hline Sweden & $0.77(0.03)$ & $0.78(0.04)$ & $0.75(0.08)$ & $0.77(0.04)$ & $0.87(0.09)$ & $0.72(0.10)$ & $0.78(0.03)$ & $0.05(0.04)$ \\
\hline United Kingdom & $0.46(0.06)$ & $0.35(0.06)$ & $0.71(0.16)$ & $0.59(0.06)$ & $0.84(0.05)$ & $0.45(0.03)$ & $0.57(0.03)$ & $0.17(0.03)$ \\
\hline \multicolumn{9}{|l|}{ Column summary } \\
\hline$M$ & $0.78(0.02)$ & $0.76(0.01)$ & $0.80(0.02)$ & $0.80(0.01)$ & $0.75(0.04)$ & $0.76(0.02)$ & & \\
\hline$S D$ & $0.11(0.02)$ & $0.14(0.02)$ & $0.14(0.01)$ & $0.07(0.02)$ & $0.20(0.02)$ & $0.12(0.01)$ & & \\
\hline
\end{tabular}

a Standard errors are given in parentheses.

profitability varies across both countries and sectors. For example, Finland is the country with the highest across-sector variation $(3.30, S E=0.62)$, whereas in Italy differences across sectors are only slight $(S D=0.81, S E=0.16)$. Sector I (Services) shows the largest across-country variation in profitability, whereas sector $\mathrm{H}$ (Finances) has the lowest variation.

Regarding persistence, Table 12 shows that Austria and Finland are the countries with the highest IP, $0.88(S E=0.02)$ and $0.87(S E=0.03)$, respectively. The United Kingdom is clearly the country with the lowest average persistence (IP $=0.57, S E=0.03$ ), with a value that deviates significantly from the other countries. Similarly, the United Kingdom and Ireland have the highest cross-sector variation in persistence ( $S D=0.17$ for both countries), whereas Belgium and Spain show lower variation in persistence across sectors $(S D=0.03)$. Sector $\mathrm{H}$ shows higher between-country variation in persistence $(0.20, S E=0.02)$ than $\mathrm{FG}$, which shows more homogeneity $(0.07, S E=0.02)$.

From Table 11, we can assess the relative magnitude of variation across countries and sectors and thus gain information on possible confounding among country and industry effects. We estimate the overall mean $\mu$ and the variance $V$ across cells (with the standard errors), as well as the percentage of variation of mean profitability $\left(\mu_{g}\right)$ across countries (columns) and across industries (rows). Table 13 shows the variance decomposition across countries and sectors, as well as the percentage explained by each component (second column of the Table). The amount of variance shared by countries and sectors (CS overlap) is also presented. The percentages of variance explained by countries and sectors are very similar to each other $(69 \%, S E=13$, and $71 \%, S E=7$, respectively), with the overlap $(2.52, S E=1.33)$ being $41 \%$ of the total variation accounted for by sectors and countries. This overlap could be explained by the particular configuration of industries across countries (as attested by the large value of Cramer's V and the $\chi^{2}$ test of independence carried out on Table 5). This is in accordance with previous studies that report interaction between country and sector effects (see, for example, Makino et al., 2004).

The reported percentage of country and industry variance components in the second column of Table 13 is relative to an overall variation that excludes the firm effects (that is, firm variation was collapsed to zero in each cell of the table). To compare country, industry, and firm effects, Table 13 
Table 13. Variance Decomposition ( $C$ is Country, $S$ is Sector, and $F$ is Firm)

\begin{tabular}{lccr}
\hline & & \multicolumn{2}{c}{ \% with respect to } \\
\cline { 3 - 4 } & Variance & \multicolumn{1}{c}{$\mathrm{C}+\mathrm{S}$} & $\mathrm{C}+\mathrm{S}+\mathrm{F}$ \\
\hline $\mathrm{C}$ & $4.28(1.69)$ & $69(13)$ & $1.30(0.30)$ \\
$\mathrm{S}$ & $4.37(1.38)$ & $71(7)$ & $1.40(0.30)$ \\
$\mathrm{C}+\mathrm{S}$ & $6.12(1.63)$ & 100 & $1.90(0.30)$ \\
CS overlap & $2.52(1.33)$ & $4 I(12)$ & $0.80(0.30)$ \\
$\mathrm{F}$ & $317.01(71.50)$ & - & $98.10(0.30)$ \\
$\mathrm{C}+\mathrm{S}+\mathrm{F}$ & $323.13(72.88)$ & - & 100.00 \\
\hline
\end{tabular}

also shows the variance accounted for by firm effect $(317.01, S E=71.50)$. Firm variation is the result of adding the variances of $P$ and $A$ for each combination of country and sector. The percentages of country $(C)$, sector $(S)$, country-by-sector $(C+S)$, and firm $(F)$ variation over the total variation are reported in the last column of Table 13. These estimates are substantially lower than those reported in previous studies. ${ }^{18}$ Estimates of effects vary across studies because they are dependent on several factors such as the analytic technique (COV, ANOVA, or HLM), the period of study, the database (e.g., manufacturing vs. nonmanufacturing firms), or the countries analyzed (see Bowman \& Helfat, 2001; McGahan \& Porter, 2002, for a review of these issues). The slight variation across sectors that we find may be partially due to the broad first-digit SIC classification scheme used (see Chang \& Singh [2000] and McGahan \& Porter [2002] for a more detailed analysis of the influence of the SIC on the size of the effects).

\section{Country-Level Association}

To analyze whether profitability and persistence are related to the national conditions in which firms operate, we consider the correlation of IP and average ROA with country-level variables not yet entered in the analysis. This type of analysis is possible given the output of the multigroup approach (that gives estimates for each country on both mean level profitability and persistence). Adding explanatory variables overcomes one of the limitations of the traditional variance component analysis and ANOVA techniques, which do not allow a correlational analysis with explanatory variables (McGahan \& Porter, 2002). We focus on the correlations between the estimates of mean profitability $(\mu)$ and the IP and each of the explanatory variables. Table 14 lists the variables considered in the analysis. The set of explanatory variables comprises variables characterizing variation of macroeconomic conditions across the EU-15 (such as gross domestic product [GDP], IMPORT, EXPORT, level of productivity [LABPROD], level of investments [INVEST]), as well as other country characteristics that may affect profitability (level of education [EDUC], size of the country [SIZE]). We also consider variables reflecting the particular composition of industries across countries such as the industry concentration (CONC) and the number of industries (NIND). The estimates of the correlations and their standard errors were obtained using the SPA.

Table 15 reports estimates and standard errors (in parentheses below), and $z$ values for the nullhypothesis of population correlation to be zero. The first two rows report the correlation of IP with the country's average profitability (measured by the ROA) and an alternative measure of profitability, the median of return on sales (ROS). Despite the small number of countries, the association of IP with $\mu$ and ROS is significant (at the $5 \%$ level).

Table 15 shows that most of the economic variables have no significant association with persistence. Only GDP and LABPROD appear to be significantly associated with average profitability $(0.39, S E=0.15$, and $0.25, S E=0.11$, respectively). However, other country characteristics show 
Table 14. Country Variables Used in External Correlational Analysis

\begin{tabular}{ll}
\hline Label & \multicolumn{1}{c}{ Description $^{\text {a }}$} \\
\hline GDP & Gross domestic product (GDP) per capita \\
IMPORT & \% of imports from the European Union (EU) \\
EXPORT & \% of exports from the EU \\
LABPROD & GDP per hour worked \\
INVEST & Gross fixed capital formation (in \% of GDP) \\
EDUC & Expenditure on education (in \% of GDP) \\
SIZE & \% of population in the EU \\
CONC & Industry concentration ratio \\
NIND & Number of industries (fourth-digit SIC) \\
\hline
\end{tabular}

${ }^{a}$ Source: EUROSTAT.

significant correlations. EDUC is negatively related to persistence $(-0.42, S E=0.18)$ and SIZE shows negative association with both average profitability $(-0.44, S E=0.16)$ and persistence $(-0.35, S E=0.08)$. Variables related to the country configuration of industries are significantly associated with both persistence and mean profitability. This is the case of CONC, which is positively associated with persistence $(0.43, S E=0.14)$ and mean profitability $(0.57, S E=0.09)$, and NIND, which is negatively related with both measures, $-0.53(S E=0.15)$ and $-0.50(S E=$ 0.12 ), respectively. Overall, our findings indicate that variables associated with profitability are not necessarily the same as those associated with persistence.

\section{Discussion and Conclusions}

This study develops methodology for multigroup analysis that permits assessing across-group variation in addition to analyzing the peculiarities of each of the groups. The methodology is used to investigate variation across EU countries in firm profitability and persistence. In the empirical analysis, we capitalize on SEM to develop endogenous parameters that capture complex aspects of the model, such as (latent) components of profitability and an index of persistence, while heteroscedasticity among countries is taken into account. Variation across groups of endogenously derived parameters is investigated using variance decomposition type statistics.

The new methods overcome the technical limitations of other statistical techniques such as linear regression and components of variance or ANOVA previously applied in the study of profit differences and addresses some of what McGahan and Porter (2002) have identified as "opportunities for extending the variance-decomposition literature."

In contrast to studies that assume randomness in the variation across groups (countries) using either components of variance (e.g., McGahan \& Porter, 1997; Rumelt, 1991) or multilevel analysis (e.g., Bou \& Satorra, 2007; Short et al., 2006) techniques, we take a fixed-effect approach that assesses variation across groups using newly defined supplementary parameters.

In assessing across-group variation, the approach we advocate reports estimates that are somewhat similar to those that would be obtained in a multilevel analysis. For example, the row (column) summaries of Tables 11 and 12 provide summary information on mean level and variation across countries (sectors), the same type of information that would be delivered by a multilevel analysis when countries (sectors) are second-level units. However, in the application considered, involving relatively few countries (15 countries or 6 sectors), in which the assumption of interchangeability of groups (random effects) is unwarranted, the assumption of fixed effects seems more natural.

Our analysis also provides detailed information on the parameter values of the second-level units. This additional information is useful to make comparisons among countries (or sectors) and to relate 
Table 15. External Correlational Analysis: Pearson's Moment Correlations With Standard Errors and z Values

\begin{tabular}{|c|c|c|}
\hline & Persistence, IP & Mean Prof. (ROA) \\
\hline Mean Prof. $(R O A)^{a}$ & $0.61^{\mathrm{b}}$ & I \\
\hline$S E$ & $(0.14)$ & - \\
\hline$z$ value & 5.01 & - \\
\hline $\operatorname{ROS}^{c}$ & $0.37^{\mathrm{b}}$ & $0.6 \mathrm{I}^{\mathrm{b}}$ \\
\hline$S E$ & $(0.14)$ & $(0.08)$ \\
\hline$z$ value & 2.62 & 7.99 \\
\hline GDP & 0.17 & $0.39^{\mathrm{b}}$ \\
\hline$S E$ & $(.16)$ & $(.15)$ \\
\hline$z$ value & 1.07 & 2.62 \\
\hline IMP & 0.09 & -0.03 \\
\hline$S E$ & $(.25)$ & $(.12)$ \\
\hline$z$ value & 0.34 & -0.23 \\
\hline EXP & 0.16 & -.04 \\
\hline SE & $(.22)$ & $(.12)$ \\
\hline$z$ value & 0.70 & -0.34 \\
\hline LABPROD & -0.13 & $0.25^{\mathrm{b}}$ \\
\hline$S E$ & (.17) & (.II) \\
\hline$z$ value & -.75 & 2.17 \\
\hline INV & 0.34 & -.11 \\
\hline$S E$ & $(.21)$ & $(.09)$ \\
\hline$z$ value & 1.60 & -1.14 \\
\hline EDUC & $-0.42^{\mathrm{b}}$ & -0.19 \\
\hline$S E$ & $(0.18)$ & $(0.12)$ \\
\hline$z$ value & -2.27 & -1.53 \\
\hline SIZE & $-0.44^{\mathrm{b}}$ & $-0.35^{\mathrm{b}}$ \\
\hline$S E$ & $(0.16)$ & $(0.08)$ \\
\hline$z$ value & -2.74 & -4.26 \\
\hline CONC & $0.43^{\mathrm{b}}$ & $0.57^{\mathrm{b}}$ \\
\hline$S E$ & $(.14)$ & $(0.09)$ \\
\hline$z$ value & 2.99 & 6.61 \\
\hline NIND & $-0.53^{b}$ & $-0.50^{\mathrm{b}}$ \\
\hline$S E$ & $(0.15)$ & $(0.12)$ \\
\hline$z$ value & -3.52 & -4.16 \\
\hline
\end{tabular}

Note: GDP = gross domestic product; IP = indices of persistence; $\mathrm{ROA}=$ rate of return on assets.

a Mean of ROA in the country.

b Significant at the $5 \%$ level.

c Median of ROS in the country.

our results with previous studies in the variance decomposition literature. We carry out a variance decomposition of country-level features of the model (mean profitability) across countries and sectors, as exemplified in Table 13. We obtain standard errors for the percentage of explained variance to be accounted for by the different factors, and we assess the possible overlap of various effects. We also provide a methodology by which the researcher can define country-level parameters (in our application, the index of persistence) and relate them to external variables that have not been used in the model fit. Inferences regarding these associations can be made with the methods proposed.

In our analysis, we have also shown how to deal with data limitations such as the presence of missing data (i.e., firms that enter or exit from the industry), measurement errors, nonnormality, and clustering effects, elements that are all useful in this type of research. In dealing with incomplete data, this study uses ML under the assumption of MAR allowing firms to have an unequal number 
of time points (i.e., different patterns of missingness), thus alleviating problems of selection biases that alternative approaches such as pairwise and listwise deletion methods could induce. We use the procedure of Muthén and Satorra (1995) to adjust the standard errors and $\chi^{2}$ statistics to protect inferences from possible dependence of observations due to the presence of industry effects.

Other studies in the literature have investigated variation of profitability across countries, using much smaller databases or data from fewer countries, and have focused on fewer aspects of the variation of profitability than our empirical application. As reported in the Results section, we found substantial variation of firm profitability across sectors and countries and a significant overlap (interaction) of the effects. This is in agreement with findings by Khanna and Rivkin (2001) and Chang and Hong (2002), who report substantial differences in the firm and industry effects across countries and over time, and with the findings by Makino et al. (2004), who report a significant country-by-industry interaction. The decomposition of the magnitudes of permanent versus transient components is investigated by Bou and Satorra (2007) for a single country; our application reinforces and expands the results of this article by showing that such variance decomposition applies for several countries and that the relative magnitude of the components differ significantly across countries. The latter aspect is in agreement with the results reported by Jacobson and Hansen (2001) on the existence of cross-country differences in the process of convergence of abnormal returns toward the equilibrium level. Regarding persistence, our results are also in line with those of Geroski and Jacquemin (1988), Glen, Lee, and Singh (2001), and Chacar and Vissa (2005), who show that levels of persistence vary across countries, and also with McGahan and Porter $(1997,2002)$ and Hough (2006), who show differences across sectors as regard the rates of persistence. In addition to providing results in a unified model frame that reinforces findings reported by several studies, our approach gives a more detailed assessment than that of other studies; for example, comprehensive information on the magnitude of firm and industry effects for each of the EU-15 countries; test of significance for cross-country variation of the magnitude of country and firm effects; and a correlation analysis of country-profitability characteristics with country-level variables, among other additions.

As with all empirical studies, our results are not free from limitations. First, despite the large sample size of our database, we found high uncertainty in the estimates, as the large standard errors in Table 9 indicate. Firms are clustered within industries, so there is a reduction in the "effective sample size" due to the likely positive intraclass correlation of firms within the same industry. This is taken care of by the aggregate estimation approach that we adopted in computing the standard errors and $\chi^{2}$ values. However, not accounting for the nesting of firms within industry (i.e., using regular ML inferences) would clearly have introduced a bias in the estimates of standard error and $\chi^{2}$ statistics, thus leading to incorrect inferences. Such large standard errors thus represent an inherent limitation of the data set used.

Second, along with the recognized problems associated with the SIC system to allocate firms to industries or sectors (Hawawini, Subramanian, \& Verdin, 2003; McGahan \& Porter, 1997), the use of the first-digit SIC code is a coarse measure to assess industry effects. Previous studies have found that a broad industry classification diminishes the overall industry variation present in the four-digit SIC classification and tends to underestimate industry effects (Chang \& Singh, 2000; McGahan \& Porter, 1997, 2002). Our reported variation across sectors clearly lower than the industry effects reported in previous studies, may be thus partly attributed to the use of only the first-digit SIC. A more detailed industry classification would be needed to compare our cross-sector variation with the industry effect reported in previous studies. This leads us to point out a (practical) limitation in applying the multigroup model approach. The number of groups (second-level) units is limited, if we want a reasonable sample size in each group. When the number of groups is large, then the multilevel approach (Bou \& Satorra, 2007; Hough, 2006; Misangyi et al., 2006; Short et al., 2006; Short, Ketchen, Palmer, \& Hult, 2007) should be applied.

In summary, we have introduced a methodology to overcome the current limitations of the standard multigroup analysis that lacks information on variation across groups. The supplementary parameters 
we have introduced combine the advantages of standard multigroup analysis with the features of multilevel models that inform on variation across groups. The extension is useful for analyzing strategic management phenomena and in other contexts, whenever variation across groups is the focus of interest, as in cross-cultural research, international business, comparative studies, and other areas.

\section{Notes}

1. We are grateful to an anonymous reviewer for pointing out that multilevel models based on the Markov Chain Monte Carlo (MCMC) approach (see Rasbash, Steel, Browne, \& Prosser, 2004) overcome limitations of the standard multilevel analysis, such as the requirement of large sample size at the group level. Bayesian computational methodology such as MCMC is indeed an interesting development and also applies to the case of small number of groups. However, it still requires the assumption of random variation across groups with a specific distribution, in addition to a prior distribution for parameters of the model, distributional assumptions that are not required in the multigroup approach.

2. To remove the cyclical component of the economy, for the sake of simplicity, we assume that the common or equilibrium rate of return is constant in the analyzed period, although other specifications are possible, such as those proposed by Waring (1996), Brouthers (1998), and McGahan and Porter (1999).

3. Let $\gamma=g(\theta)$ be the new supplementary parameter, a function of the vector of $\theta$ of parameters of the model. We estimate $\gamma$ as $\hat{\gamma}=g(\hat{\theta})$, with the standard error obtained by the classical delta-method; that is, $S E(\hat{\gamma})=\sqrt{\dot{g}(\hat{\theta})^{\prime}[\operatorname{Var}(\hat{\theta})] \dot{g}(\hat{\theta})}$, where $\dot{g}(\hat{\theta})$ is the gradient of $g($.$) evaluated at the parameter estimates,$ $\operatorname{Var}(\hat{\theta})$ is the variance matrix of the estimator $\hat{\theta}$. Note that $g()$ could be $q$-dimensional, in which case $\operatorname{Var}(\hat{\theta})$ provides the bases for constructing a standard Wald test for hypothesis regarding a set of supplementary parameters.

4. Bootstrap bias-corrected estimates and standard errors (e.g., Davison \& Hinkley, 1997) of those supplementary parameters should be used instead of the delta method. At present, estimates and standard errors of the supplementary parameters, based on the delta-method and the variants based on the bootstrap, are currently available and in the SEM proprietary software Mplus (version 5.2; Muthén and Muthén, 2007) and LISREL (Jöreskog \& Sörbom, 1996) in the free software Mx (Neale, Boker, Xie, \& Mas, 2003). The implementation of the SPA with current software is very simple; for example, the specification of a supplementary parameter $\mathrm{sp}$ that is the mean of parameters $\mathrm{p} 1$ and $\mathrm{p} 2$ would require the following code: in Mplus,

\section{MODEL CONSTRAINT $: \mathrm{NEW}(\mathrm{sp}) ; \mathrm{sp}=(\mathrm{p} 1+\mathrm{p} 2) / 2 ;$}

in LISREL, $\mathrm{AP}=1$ in the $\mathrm{MO}$ command and $\mathrm{CO} \mathrm{AP}(1)=(\mathrm{p} 1+\mathrm{p} 2) / 2$. The full Mplus code for the analyses undertaken in the current paper is available from the first author on request.

5. We are indebted to an anonymous reviewer for the valuable suggestion to estimate group-level variance parameters using the supplementary parameter approach and for pointing out how to do so with Mplus.

6. An anonymous reviewer pointed out that our SPA is related to previous literature on phantom variables (see Cheung, 2007a; Hayduk, 1987, 1996; Loehlin, 2004; Rindskopf, 1984). We are grateful for this observation. Although phantom variables have been used to estimate nonlinear functions of parameters using standard software, we are not aware of their use to estimate parameters that assess variation across groups, as we do in this article. Furthermore, our SPA concentrates on the definition and conceptualization rather than on computational issues using traditional software, the main justification for the use of the phantom variables. Most current software for SEM analysis provides such estimates without requiring the introduction of phantom variables.

7. See http://www.bvdep.com/en/amadeus.html

8. Figures refer to update Number 126 in March 2005. 
9. (A) Agriculture, Forestry, and Fishing; (B) Mining; (C) Construction; (D) Manufacturing; (E) Transport, Communications, Electric, Gas; (FG) Wholesale (F) and Retail $(\mathrm{G})$ Trade; $(\mathrm{H})$ Finance, Insurance, and Real Estate; and (I) Services. Note that in the analysis we pooled the Wholesale Trade and Retail Trade sectors in a single sector because of the overlap between them.

10. All the $\chi^{2}$ values in this table are obtained using Muthén and Satorra's (1995) aggregate analysis, which corrects for nonnull intraclass correlation of firms within industries.

11. For some countries, $M G$ incorporates the removal of some restrictions implicit in the base-model of Figure 1. Specifically, in Austria, Denmark, France, Germany, Luxembourg, and Portugal, the model has no permanent component; and in nine countries, some of the error variances were restricted to zero (to avoid Heywood cases, negative variances), as shown in Table 9. The fit could improve if in Germany, Greece, and Portugal we allowed different variances for disturbance terms (in Germany, for years 2001 and 2003, in Greece, for years 2002 and 2003, and in Portugal for year 2001); and the equality over time of the autoregressive parameter $(\beta)$ were not imposed in Germany for 2001 and 2003 or in Portugal for 2001. The last two restrictions were not imposed to avoid changing the conceptual definition of the transitory component and of the IP index introduced in Equation 5. We feel this is a circumstance where the fit of the model should be sacrificed for the sake of comparability across countries.

12. All the $\chi^{2}$ values reported correspond to the scaled goodness-of-fit test statistic of Satorra and Bentler (1994; see also Muthén \& Satorra, 1995). The scaled difference is not equal to the difference of scaled $\chi^{2}$ statistics, so we need to use the procedure of Satorra and Bentler (2001) to compute the appropriate scaled difference test statistic. See Crawford (2002) for online software that assists in computing the scaled $\chi^{2}$ difference test statistic.

13. As reported above, six countries lack the permanent component of profitability.

14. We are grateful to an anonymous reviewer for this observation.

15. Tables 9 and 10 were obtained for each group, although they are not reported for the sake of space. These additional tables are available from the authors on request.

16. We are grateful to an anonymous reviewer for observing that the unequal sample sizes across countries influence the estimation of across-group parameters and for suggesting that model parameters should be estimated by weighting each group by their sample size. However, our interest is to assess the variation across the $15 \mathrm{EU}$ countries assuming all the countries are equally important in the comparison and are therefore associated with equal weights. This is a substantive decision that might be different in an altered context. The same methodology applies when unequal weights for the countries are given. In the Amadeus database, used in this research, different criteria for inclusion of firms are applied in the countries, and the number of firms included is a poor proxy for the size of the country's economy. For example, Germany has fewer firms in the sample than would correspond to its economic weight in the EU. The weights derived from the country's representation in the data would not be suitable for assessing the variation.

17. Note that means in row summaries differ from the estimates of country mean profitability and IPs reported, respectively, in Table 9 due to the unequal distribution of firms into sectors across countries.

18. Past research reports industry effects that range from $4 \%$ (Rumelt, 1991) to $18.7 \%$ (McGahan \& Porter, 1997).

\section{Acknowledgments}

The authors are indebted to the associate editor Donald D. Bergh and two anonymous reviewers for very generous and constructive comments that have made possible the current version of the article. The comments by Nick T. Longford on an earlier draft of this paper are appreciated.

\section{Declaration of Conflicting Interests}

The authors declared no potential conflicts of interests with respect to the authorship and/or publication of this article. 


\section{Funding}

The authors disclosed receipt of the following financial support for the research and/or authorship of this article: Partially supported by grants SEJ2006-13537 and PR2007-0221 from the Spanish Ministry of Science and Technology and by grants GV05/125 and BEST/2008/038 from the Generalitat Valenciana (Spain).

\section{References}

Anderson, T. W., \& Hsiao, C. (1982). Formulation and estimation of dynamic models using panel data. Journal of Econometrics, 18, 47-82.

Benston, G. (1985). The validity of profits-structure studies with particular reference to the FTC's line of business data. American Economic Review, 75, 37-67.

Blaine, M. (1994). Comparing the profitability of firms in Germany, Japan, and the United States. Management International Review, 34, 125-148.

Bou, J. C., \& Satorra, A. (2007). The persistence of abnormal returns at industry and firm levels: Evidence from Spain. Strategic Management Journal, 28, 707-722.

Bowman, E. H., \& Helfat, C. (2001). Does corporate strategy matter? Strategic Management Journal, 22, 1-23.

Brouthers, L. E. (1998). Explaining MNC profitability: Country-specific, industry-specific and countryindustry interactive influences. Management International Review, 38, 345-361.

Brush, T. H., \& Bromiley, P. (1997). What a small corporate effect mean? A variance components simulation of corporate and business effects. Strategic Management Journal, 18, 825-835.

Brush, T. H., Bromiley, P., \& Hendrickx, M. (1999). The relative influence of industry and corporation on business segment performance: An alternative estimate. Strategic Management Journal, 20, 519-547.

Bureau Van Dijk. (2005). Amadeus. Amsterdam: Bureau van Dijk Electronic Publishing. Retrived Novenber 28, 2005, from http://www.bvdep.com/en/amadeus.html

Cañibano, L., \& Mora, A. (2000). Evaluation the statistical significance of de facto accounting harmonization: A study of European global players. The European Accounting Review, 9, 349-369.

Chacar, A., \& Vissa, G. (2005). Are emerging economies less efficient? Performance persistence and business group affiliation. Strategic Management Journal, 26, 933-946.

Chan, D. (1998). The conceptualization of change over time: An integrative approach incorporating longitudinal means and covariance structures analysis (LMACS) and multiple indicator latent growth modeling (MLGM). Organizational Research Methods, 1, 421-483.

Chang, S. J., \& Hong, J. (2002). How much does the business group matters in Korea? Strategic Management Journal, 23, 265-274.

Chang, S. J., \& Singh, H. (2000). Corporate and industry effects on business unit competitive position. Strategic Management Journal, 21, 739-752.

Cheung, G. W., \& Rensvold, R. B. (1999). Testing factorial invariance across groups: A reconceptualization and proposed new method. Journal of Management, 25, 1-27.

Cheung, M. W. L. (2007a). Comparison of approaches to constructing confidence intervals for mediating effects using structural equation models. Structural Equation Modeling, 14, 227-246.

Cheung, M. W. L. (2007b). Comparison of methods of handling missing time-invariant covariates in latent growth models under the assumption of missing completely at random. Organizational Research Methods, 10, 609-634.

Choi, F. D., Hino, H., Min, S. K., Nam, S. O., Ujiie, J., \& Stonehill, A. I. (1983). Analyzing foreign financial statements: The use and misuse of international ratio analysis. Journal of International Business Studies, 14, 113-131.

Christmann, P., Gray, D., \& Yip, G. S. (1999). The relative influence of country conditions, and business strategy on multinational corporation subsidiary performance. Journal of International Management, 5, 241-265. 
Crawford, J. R. (2002). SBDIFF.EXE, computer program for Satorra-Bentler scaled difference chi-square. Retrieved November 30, 2008, from http://www.abdn.ac.uk/ psy086/dept/sbdiff.htm

Davison, A. C., \& Hinkley, D. V. (1997). Bootstrap methods and their application. UK: Cambridge University Press.

Demsetz, H. (1979). Accounting for advertising as a barrier to entry. Journal of Business, 59, 345-360.

Fisher, F. M., \& McGowan, J. J. (1983). On the misuse of accounting rates of return to infer monopoly profits. American Economic Review, 73, 82-97.

Geroski, P. A., \& Jacquemin, A. (1988). The persistence of profits: A European comparison. The Economic Journal, 98, 375-389.

Glen, J., Lee, K., \& Singh, A. (2001). Persistence of profitability and competition in emerging markets. Economic Letters, 72, 247-253.

Hawawini, G., Subramanian, V., \& Verdin, P. (2003). Is performance driven by industry- or firm-specific factors? A new look at the evidence. Strategic Management Journal, 24, 1-16.

Hayduk, L. A. (1987). Structural equation modeling with LISREL: Essentials and advances. Baltimore: The Johns Hopkins University Press.

Hayduk, L. A. (1996). LISREL: Issues, debates, and strategies. Baltimore: The Johns Hopkins University Press.

Hough, R. (2006). Business segment performance redux: A multilevel approach. Strategic Management Journal, 27, 45-61.

Hult, G. T. M., Ketchen, D. J., Griffinth, D. A., Chabowski, B. R., Hamman, M. K., Dykes, B. J., et al. (2008). An assessment of the measurement of performance in international business research. Journal of International Business Studies, 39, 1064-1080.

Jacobson, R. (1988). The persistence of abnormal returns. Strategic Management Journal, 9, 415-430.

Jacobson, R., \& Hansen, G. (2001). Modeling the competitive process. Managerial and Decision Economics, 22, 251-263.

Jöreskog, K. J., \& Sörbom, D. (1996). LISREL 8: Users reference guide. Chicago: SSI Scientific Software International, Inc.

Kenny, D., \& Zautra, A. (1985). The trait-state-error model for multi-wave data. Journal of Consulting and Clinical Psychology, 63, 52-59.

Kenny, D., \& Zautra, A. (2001). Trait-state models for longitudinal data. In L. M. Collins \& A. G. Sayer (Eds.), New methods for the analysis of change (pp. 243-263). Washington: American Psychological Association.

Khanna, T., \& Rivkin, J. W. (2001). Estimating the performance effects of business groups in emerging markets. Strategic Management Journal, 22, 45-74.

Krisement, V. M. (1997). An approach for measuring the degree of comparability of financial accounting information. The European Accounting Review, 6, 465-485.

Little, T. D. (1997). Mean and covariance structures (MACS) analyses of cross-cultural data: Practical and theoretical issues. Multivariate Behavioral Research, 32, 53-76.

Loehlin, J. C. (2004). Latent variable models: An introduction to factor, path, and structural equation analysis (see Appendix E, p. 256), London: Lawrence Erlbaum Associates.

Makino, S., Isobe, T., \& Chan, C. M. (2004). Does country matter? Strategic Management Journal, 25, 1027-1043.

McArdle, J. J., \& Hamagami, F. (1996). Multilevel models from a multiple group structural equation perspective. In G. A. Marcoulides \& R. E. Schumacker (Eds.), Advanced structural equation modeling: Issues and techniques (pp. 89-124). Mahwah, NJ: Lawrence Erlbaum Associates.

McGahan, A. M., \& Porter, M. E. (1997). How much does industry matter, really? Strategic Management Journal, 18, 15-30.

McGahan, A. M., \& Porter, M. E. (1999). The persistence of shocks to profitability. Review of Economics and Statistics, 81, 143-153.

McGahan, A. M., \& Porter, M. E. (2002). What do we know about variance in accounting profitability. Management Science, 48, 834-851. 
Misangyi, V. F., Elms, H., Greckhamer, T., \& Lepine, J. A. (2006). A new perspective on a fundamental debate: A multilevel approach to industry, corporate, and business unit effects. Strategic Management Journal, 27, 571-590.

Mueller, D. C. (1986). Profits in the long run. UK: Cambridge University Press.

Mueller, D. C. (1990). The dynamics of company profits: An international comparison. UK: Cambridge University Press.

Muthén, B. O., \& Satorra, A. (1995). Complex sample data in structural equation modeling. Sociological Methodology, 25, 267-316.

Muthén, B. O., \& Muthén, L. K. (2007). Mplus user's guide (5th ed.). Los Angeles: Muthén \& Muthén.

Neale, M. C., Boker, S. M., Xie, G., \& Maes, H. H. (2003). Mx: Statistical modeling (6th ed.). Richmond, VA: Department of Psychiatry.

Nobes, C., \& Parker, R. (2006). Comparative international accounting. essex. UK: Prentice Hall.

Ployhart, R. E., \& Oswald, F. L. (2004). Applications of mean and covariance structure analysis: Integrating correlational and experimental approaches. Organizational Research Methods, 7, $27-65$.

Rasbash, J., Steel, F., Browne, W., \& Prosser, B. (2004). A user's guide to MLwiN. London: Centre for Multilevel Modelling, Institute of Education, University of London.

Rindskopf, D. (1984). Using phantom and imaginary latent variables to parameterize constraints in linear structural models. Psychometrika, 49, 37-47.

Roquebert, J. A., Phillips, R. L., \& Westfall, P. A. (1996). Markets vs. management: What “drives” profitability? Strategic Management Journal, 17, 653-664.

Rubin, D. B. (1976). Inference and missing data. Biometrika, 63, 581-592.

Rumelt, R. P. (1991). How much does industry matter? Strategic Management Journal, 12, 167-185.

Satorra, A. (2002). Asymptotic robustness in multiple group linear-latent variable models. Econometric Theory, $18,297-312$.

Satorra, A., \& Bentler, P. M. (1994). Corrections to test statistics and standard errors in covariance structure analysis. In A. von Eye \& C. C. Clogg (Eds.), Latent variables analysis: Applications for developmental research (pp. 399-419). Thousand Oaks, CA: Sage.

Satorra, A., \& Bentler, P. M. (2001). A scaled difference chi-square test statistic for moment structure analysis. Psychometrika, 66, 507-514.

Schmalensee, R. (1985). Do markets differ much? American Economic Review, 12, 341-351.

Short, J. C., Ketchen, D. J., Bennett, N., \& du Toit, M. (2006). An examination of firm, industry, and time effects on performance using random coefficient modeling. Organizational Research Methods, 9, 259-284.

Short, J. C., Ketchen, D. J., Palmer, T. B., \& Hult, T. M. (2007). Firm, strategic group, and industry influences on performance. Strategic Management Journal, 28, 147-167.

Vandenberg, R. J., \& Lance, C. E. (2000). A review and synthesis of the measurement invariance literature: Suggestions, practices, and recommendations for organizational research. Organizational Research Methods, 3, 4-70.

Waring, G. (1996). Industry differences in the persistence of firm-specific returns. American Economic Review, $86,1253-1265$.

Wernerfelt, B., \& Montgomery, C. A. (1988). Tobin's q and the importance of focus in firm performance. American Economic Review, 78, 246-250.

Wiggings, R., \& Ruefli, T. (2002). Sustained competitive advantage: Temporal dynamics and the incidence and persistence of superior economic performance. Organization Science, 13, 82-105.

\section{Bios}

Juan Carlos Bou is an associate professor at the Department of Business Administration at the Universitat Jaume I (Castelló, Spain). His primary research interest is in quality management and business strategy, an area 
where he has published in leading journals (Strategic Management Journal, Journal of Management, Journal of Operation Management, among others).

Albert Satorra is professor of statistics at the Department of Economics and Business, Universitat Pompeu Fabra, Barcelona. His area of expertise is structural equation modeling, a topic in which he has contributed with numerous articles in leading journals. He is an associate editor of psychometrika and of structural equation modeling. 